\title{
COOPERATIVAS DE CRÉDITO Y BANCA SOCIAL: VIEJAS Y NUEVAS RESPUESTAS ÉTICAS Y SOLIDARIAS A PROBLEMAS DE SIEMPRE
}

\author{
POR \\ Francisco SOLER TORMO y \\ Amparo MELIÁN NAVARRO ${ }^{1}$
}

\section{RESUMEN:}

Entre el origen de las cooperativas de crédito y la nueva "banca social" median unos cien años, en los que los sistemas bancarios han sufrido una transformación extraordinaria. A pesar de sus diferencias, ambos tipos de instituciones surgieron por unos motivos semejantes: la exclusión financiera de colectivos vulnerables y la necesidad de respuestas éticas, solidarias y responsables. Esas necesidades han cobrado protagonismo con la actual crisis financiera, económica y social, en la que se aprecia un deterioro de los valores elementales y, en consecuencia, una extensión del descrédito de las entidades bancarias. En esta situación, se revaloriza el papel del crédito cooperativo y de la "banca social", instrumentos que, por sus especiales características, se han visto menos afectadas por la pérdida de reputación y se abren paso como alternativas.

Palabras clave: Banca ética, Crédito cooperativo, Crisis financiera, Proyecto Fiare, Responsabilidad social,

Claves Econlit: G010; G210; L260;

1 Francisco Soler Tormo: IUDESCOOP
$\begin{aligned} & \text { Francisco.Soler@uv.es } \\ & \text { Amparo Melián Navarro: Unitat de València. Dirección de correo electrónico: } \\ & \text { amparo.melian@umh.es }\end{aligned}$ REVESCO No 109 - MONOGRÁFICO: La financiación complementaria y la respuesta de la economía social: la situación del "des-crédito" bajo la crisis financiera -

ISSN: 1885-8031 - www.ucm.es/info/revesco

http://dx.doi.org/10.5209/rev_REVE.2012.v109.40655

Fecha de recepción: 18/05/2012

Fecha de aceptación: 29/11/2012 


\title{
CREDIT COOPERATIVES AND SOCIAL BANKING: OLD AND NEW ETHICAL AND SOLIDARITY RESPONSES TO USUAL PROBLEMS
}

\begin{abstract}
:
Between the credit cooperatives origin and new social banking have passed by a century, in which banking systems have going through an extraordinary change. Despite their differences, both kinds of companies come up by similar reasons: Financial exclusion of vulnerable collectives and need of ethical, responsible and solidary responses. These needs have gain prominence in the present social and financial-economic crisis, in which a basic values deterioration and accordingly a growing essential values deterioration. In this situation increase the social banking and cooperative credit role. These tools have been less affected by loos of reputation because of their especial features and breaking through as new credit ways.
\end{abstract}

Key words: Ethical banking, Credit cooperative, Financial crisis, Fiare project, Social liabilities

\section{INTRODUCCIÓN}

Del mismo modo que los sistemas financieros han ido permanentemente adaptándose a su entorno económico, generando instituciones que respondieran en cada momento a las demandas de crédito de los sectores más lucrativos, los excluidos de estos canales han desplegado iniciativas solidarias, adaptadas a sus circunstancias. De este modo, ha ido transformándose la fisonomía de los sistemas bancarios capitalistas y, paralelamente, han ido surgiendo iniciativas de crédito y ahorro popular inspiradas en la cooperación.

Este proceso adaptativo ha sido más dinámico que la respuesta de los legisladores. El anterior gran cataclismo financiero, el de la década de los años 1930, sentó las bases de una regulación que asumía la necesidad de un control prudencial sustentado en cuatro pilares: el establecimiento de seguros de garantía de depósitos, la provisión de liquidez por la autoridad monetaria, la separación de la banca de inversión y de depósito y el mantenimiento de unos niveles mínimos de solvencia. Con ella se configuró un marco estable que propició el 
crecimiento en el mundo occidental posbélico hasta la crisis de los años setenta, en lo que se ha llamado el "paradigma de la modernidad" basado en la conjunción del mercado y un sector público encargado de ordenar activamente la actividad económica.

La oleada neoliberal de los ochenta dio un nuevo impulso al crecimiento al amparo de la globalización, pero simultáneamente generó una serie de efectos perversos, como el sobredimensionamiento de la actividad financiera, el incremento de las desigualdades y, en consecuencia, el aumento de los excluidos. Se llevó al extremo el objetivo de maximización de beneficios, olvidando cualquier consideración social, mediante la ficción de "originar para distribuir". Se extendió la idea de que cualquier tipo de regulación distorsionaba la "mano invisible", por lo que se abogó por la liberalización, la flexibilización y la discrecionalidad en la gobernanza de las empresas, confiando en que los mercados generarían espontáneamente mecanismos que garantizarían la estabilidad y el equilibrio del sistema. En consecuencia se fue desmantelando el entramado legislativo que surgió a partir de los años treinta, dejando a los agentes privados la capacidad de ejercer de jueces en el sistema cada vez más complejo que ellos mismos habían creado.

La evidencia posterior puso en duda la supuesta racionalidad de los agentes. El resultado se mostró claramente a partir de 2007: la sucesión de una cadena de quiebras financieras y la sensación de que el capitalismo, en su versión extrema, había incumplido sus promesas y había generado desigualdad, desempleo y degradación de los valores (Stiglitz, 2012).

En esta deriva existe la opinión, más o menos generalizada, de que la banca ha sido la principal responsable de la crisis. O mejor, aquellos banqueros que, llevados por la obsesión de multiplicar el dinero, han llevado a la economía real a un callejón sin salida. Al margen de si esta afirmación es totalmente cierta, es evidente que la imagen del "banquero" ha experimentado una notable devaluación: del respetable y prudente de levita negra, al yuppy émulo de tiburón que se enriquece arruinando lo que le rodea. Como ilustrativamente recoge Tom Wolfe (1987) en La Hoguera de las Vanidades con el pletórico de avidez que a la pregunta de por cuánto dejaría su actividad contestaba: "por más". Daba la impresión de que el libre mercado, desprovisto de regulación, tendía a debilitar la moralidad de sus agentes.

REVESCO No 109 - MONOGRÁFICO: La financiación complementaria y la respuesta de la economía social: la situación del "des-crédito" bajo la crisis financiera -

ISSN: 1885-8031 - www.ucm.es/info/revesco 
¿Ha sido este comportamiento generalizado? Sin duda no, pero da la impresión que casi. Si bien una serie de factores contribuyeron a una embriaguez de crédito y a la difusión de comportamientos oportunistas atraídos por el dinero fácil, especialmente entre las empresas imbuidas del boom inmobiliario y financiero, la intensidad y los efectos devastadores de la crisis fue muy desigual, en concreto entre los distintos tipos de intermediarios financieros. De hecho, entre las cooperativas de crédito apenas ha habido repercusión mediática, permaneciendo al margen de los grandes escándalos y de los costosos planes de recapitalización. En el lado opuesto, las cajas de ahorros prácticamente han sido borradas del mapa financiero español.

El escenario que se avecina presenta numerosas incertidumbres. ¿Son las cooperativas una alternativa? Sin duda alguna, una vez capeado el temporal de la crisis, nos esperan nuevos planteamientos, nuevos modelos. Las nuevas demandas de los excluidos parecen reclamar una respuesta desde abajo, basada en valores de solidaridad y cooperación. Asimismo, una sociedad más informada y sensibilizada reclama unas finanzas más justas y responsables. Ahora bien, si algo hemos aprendido de todo este marasmo es que, en primer lugar, no aprendemos de las lecciones de la historia, y, en segundo, que somos incapaces de realizar ni los pronósticos más evidentes.

Por tanto, dado que el futuro, por suerte o por desgracia, "no está escrito en las estrellas" ni en las conclusiones de los modelos más complejos, hay que resignarse a mirar hacia atrás para ver qué se ha hecho bien o mal y qué circunstancias han atenuado o acelerado la, sin duda, pérdida de credibilidad del sistema financiero. Para ello, en primer lugar, trataremos de mostrar el momento y las razones por las que nace la preocupación por la responsabilidad social en el sistema financiero, como elemento de reputación, y cómo a pesar de ello se ha ido deteriorando su imagen paulatinamente, y de forma acelerada con la crisis. En segundo lugar, se analiza brevemente el componente social de las cooperativas de crédito y se plantea la hipótesis, aunque no su constatación, de que precisamente sus principios esenciales, que hasta el momento habían sido valorados como una traba para competir con el resto de intermediarios financieros, las han aislado en cierta medida de los efectos de la crisis y del descrédito general. Algo semejante ocurre con iniciativas que irrumpen, pese a las 
dificultades, y que se engloban en lo que se ha venido en llamar "banca social", alentadas por una demanda de moralidad por parte de la sociedad civil.

En consecuencia, el objetivo de este trabajo es reflexionar sobre la importancia de los valores de ética y de responsabilidad entre las entidades de crédito, en especial, entre las cooperativas, que precisamente tienen en ellos su razón de ser. La necesidad de revalorizarlos se ha puesto de manifiesto a lo largo de la gestación y eclosión de la crisis, tomando fuerza, como respuesta, nuevas experiencias que tienen como elemento definitorio esos mismo valores. Como ejemplo destacado de estas iniciativas se muestra el proyecto Fiare, en el que se pone de manifiesto el entusiasmo de muchas instituciones de la economía social por buscar soluciones solidarias, ante el deterioro de los colectivos más desfavorecidos de nuestro país. El trabajo se completa con las conclusiones y las referencias bibliográficas.

\section{RESPONSABILIDAD SOCIAL EN EL SECTOR BANCARIO}

La preocupación en el ámbito de las grandes empresas por la reputación empresarial cimentada en comportamientos éticos surgió a medida que el "poder de mercado" se desprendía de la "tiranía de las regulaciones" en las últimas décadas del siglo XX. En este sentido, el influjo del neoliberalismo y la impronta de Milton Friedman eran evidentes. Para el profesor de Chicago, la responsabilidad social de una empresa consiste únicamente en producir beneficios para sus accionistas, ya que la competencia del propio mercado protege al consumidor mucho mejor que los mecanismos gubernamentales, gracias a su capacidad de generar dispositivos eficientes que garanticen las demandas de los agentes económicos, no sólo relativas a la calidad de los productos sino también a cómo se han producido. Básicamente estos dispositivos son la propia acción de los detallistas en su actividad comercial, la reputación de las marcas o las agencias privadas de comprobación (Friedman, 1980). El retroceso de lo público se acompaña de un esfuerzo por mostrar la capacidad de lo privado para desprenderse de su pátina de individualismo egoísta y para responder a los valores elementales de convivencia.

A pesar de ello, frecuentemente las prácticas empresariales aislaron peligrosamente la gestión - que debía además de incrementar la riqueza de los propietarios, proporcionar seguridad y prosperidad al resto de los agentes involucrados - de los principios éticos más REVESCO No 109 - MONOGRÁFICO: La financiación complementaria y la respuesta de la economía social: la situación del "des-crédito" bajo la crisis financiera -

ISSN: 1885-8031 - www.ucm.es/info/revesco 
elementales. La repercusión mediática de escándalos financieros, sociales o medioambientales provocó la sensibilización de una parte cada vez mayor de la sociedad y la consiguiente difusión de una nueva mentalidad empresarial, una "oleada ética" fundada en el respeto de determinados valores morales y en la coherencia entre los fines y los medios.

Se desarrolló, así, un mercado para la ética (markética) basado en la imagen mediática con el fin de ejercer una influencia positiva entre los clientes potenciales (Lipovetsky, 2002). Ahora bien, los confines de la ética se impregnan de estética, cuando no de cosmética. Para una empresa lucrativa, la responsabilidad social puede ser valorada desde la perspectiva costebeneficio. Por una parte, la práctica de la generosidad o la filantropía es un gasto que puede aumentar la reputación y, por tanto, los ingresos (Olmedo et al., 2012). Por otra parte, el seguimiento de criterios éticos en la gestión cotidiana evita confrontaciones con la sociedad civil, sobre todo si está concienciada o es beligerante con el respeto de los bienes públicos (Velásquez, 2006).

El sector financiero no ha sido ajeno a esta problemática. No hay que olvidar que es uno de los segmentos de la economía que tradicionalmente ha estado más regulado y supervisado, lo que se debe a varias razones. En primer lugar, en la sociedad actual el crédito y el ahorro se ha convertido en una de las necesidades básicas para el conjunto de la población. En segundo lugar, a la hora de desarrollar dichas actividades se produce un desequilibrio entre los agentes debido a la asimetría informativa. Finalmente, por su capacidad de generar dinero y de canalizar recursos, constituye un elemento clave dentro del equilibrio macroeconómico. En consecuencia, la estabilidad del sistema financiero se considera un auténtico bien público, cuyo fracaso acarrea severas consecuencias para el conjunto de la economía ${ }^{2}$.

Por estas razones ha existido una especial sensibilidad hacia los escándalos financieros, generando una repulsa acentuada. En estos escándalos, que los ha habido tanto a nivel

\footnotetext{
${ }^{2}$ Por ese motivo, la crisis financiera, en un contexto de retroceso regulador, ha generado la exclusión de los necesitados de crédito, ha provocado la indignación de unos usuarios que se han sentido estafados y ha acentuado de forma extraordinaria los grandes desequilibrios macroeconómicos. A ello se añade la perplejidad de ver cómo se recortan recursos para necesidades básicas mientras se anuncian millonarias ayudas para el reflotamiento de los bancos.
}

REVESCO No 109 - MONOGRÁFICO: La financiación complementaria y la respuesta de la economía social: la situación del "des-crédito" bajo la crisis financiera -

ISSN: 1885-8031 - www.ucm.es/info/revesco 
nacional como internacional, y sin ánimo de enumerarlos, normalmente se conjugan una serie de elementos que los hacen más dañinos:

a) Dado que su actividad se basa en la captación de recursos de sus clientes, ante situaciones de debilidad las entidades financieras han tendido a llevar a cabo una "huida hacia delante", cubriendo con nuevos fondos, atraídos por dulces promesas, las deficiencias acumuladas. Ejemplos no faltan: desde Ruiz Mateos en sus sendas crisis (1983 y 2011) a las prácticas de ahorro piramidal que ocultaban el Fórum Filatélico (2006) o Madoff (2008), pasando por Mario Conde y la Corporación Banesto (1993).

b) Amplio espectro de su ámbito de influencia, lo que permite al sistema financiero imbricar la economía formal y legal con los canales alegales. De hecho, la gran banca no ha tenido ningún rubor a la hora de mantener establecimientos en los "paraísos fiscales", incluso en gestionar en ellos los fondos de pensiones de sus propios directivos (caso BBVA, 1987-2001).

c) La complejidad creciente a la que se ha visto sometido el negocio bancario con la aparente finalidad de mejorar la rentabilidad y la seguridad, ha desembocado en abusos de "contabilidad creativa" que, en el fondo no hacen más que ocultar la realidad patrimonial. Simultáneamente, la regulación no solo no se adaptaba a la mayor complejidad, sino que deliberadamente se relajaba. El caso paradigmático fue el escándalo de Enron (2001), que arrastró tras de sí a la entonces auditora de mayor reputación, Arthur Andersen. Por otra parte, las innovaciones financieras como la titulización o la securitización permitieron una transferencia y una redistribución del riesgo hacia quienes no eran conscientes del mismo. El colofón se produjo cuando en 2008 estallaba el escándalo de Lehman Brothers, una inmensa estafa en la que participaron calificadores y calificados. A la postre, los ahorradores se sintieron engañados al suscribir activos de riesgo confiados en la seguridad de quien se los ofrecía (caso de las cuotas participativas o las "preferentes").

d) Fallos de gobierno o desequilibrios entre los órganos de poder de las entidades. La consolidación de los grandes conglomerados acentuó la asimetría informativa y de poder a favor de los altos directivos. El abuso en interés propio de esta situación no solo atenta a la noción de justicia, entendida como el equilibrio en la preservación de los intereses de los diferentes colectivos implicados en la empresa, sino que, además, pone en peligro la viabilidad de la propia entidad. Para alcanzar los objetivos 
prefijados por los directivos se siguió el "todo vale" y, en consecuencia, se justificaron prebendas extraordinarias. En España el primer gran escándalo de este tipo se remonta a las tristemente famosas stock options de Telefónica, que tuvieron su continuidad en la banca con las indemnizaciones extraordinarias de Amusátegui y Coscóstegui (2005), que preludiaron la avalancha de abusos que se pusieron de manifiesto cuando las entidades intervenidas por la crisis dieron a conocer su política retributiva. Los "bonus" como sistema de recompensa a directivos fueron desde el principio asimétricos e incompletos, al no incluir los "malus" cuando se puso de manifiesto la nefasta gestión. El propio presidente norteamericano Obama habló de poner fin a "la era de la irresponsabilidad".

e) Difusión de la cultura del enriquecimiento fácil, también llamada "cultura del pelotazo", que desde el precursor Javier de la Rosa (1994) se difundió al amparo del desenfreno inmobiliario. Ambiciosos timadores gozaron de la aquiescencia general, cuando no del prestigio de los triunfadores. La tentación de alianza entre los espabilados oportunistas y políticos ambiciosos desembocó en sonados casos de corrupción.

Ante este deterioro de la credibilidad, las grandes empresas bancarias han recurrido a mostrar su cara más amable, recurriendo a la difusión de sus memorias de responsabilidad social corporativa y sus informes de sostenibilidad. Con ello tratan de recomponer su imagen y cimentar su amenazada reputación.

No obstante, si se exceptúan los tres principales bancos, se aprecia un considerable deterioro de la reputación del sistema bancario español (tabla 1). Este fenómeno se puede observar a través del indicador elaborado por Merco, el proyecto de investigación universitaria patrocinado por Villafañe y Asociados, con la colaboración del Instituto Español de Analistas Financieros, ONGs, sindicatos y el periódico Cinco Días.

Tabla 1. Posición de los bancos españoles en el Ranking MERCO. Monitor Español de Reputación Corporativa.

\begin{tabular}{|l|c|c|c|c|c|c|c|c|c|c|}
\hline & 2012 & 2011 & 2010 & 2009 & 2008 & 2007 & 2006 & 2005 & 2004 & 2003 \\
\hline B. Santander & 4 & 1 & 2 & 4 & 5 & 6 & 6 & 6 & 6 & 6 \\
\hline BBVA & 11 & 8 & 7 & 8 & 7 & 5 & 5 & 5 & 5 & 5 \\
\hline CaixaBank & 7 & 5 & 4 & 6 & 6 & 7 & 7 & 7 & 7 & 13 \\
\hline
\end{tabular}

REVESCO No 109 - MONOGRÁFICO: La financiación complementaria y la respuesta de la economía social: la situación del "des-crédito" bajo la crisis financiera -

ISSN: 1885-8031 - www.ucm.es/info/revesco 


\begin{tabular}{|l|c|c|c|c|c|c|c|c|c|c|}
\hline Bankia & 86 & 41 & 20 & 11 & 11 & 12 & 13 & 14 & 19 & 27 \\
\hline Bankinter & 70 & 56 & 21 & 45 & 15 & 18 & 20 & 18 & 13 & 9 \\
\hline B. Popular & 79 & 63 & 51 & 47 & 23 & 19 & 21 & 17 & 8 & 7 \\
\hline Banesto & 87 & 81 & 38 & 36 & 50 & 34 & 34 & 55 & 56 & \\
\hline B. Sabadell & 64 & 59 & 61 & 68 & 55 & 41 & 46 & 39 & 53 & \\
\hline B. Cívica & & 94 & 41 & 65 & 66 & & & & & \\
\hline Bancaja & & 61 & 49 & 61 & 36 & 43 & 55 & 75 & & \\
\hline C. Catalunya & & & 94 & 87 & 72 & 91 & & & & \\
\hline ING Direct & 73 & 57 & 57 & 70 & 47 & 59 & 61 & 81 & & \\
\hline Kutxa Guip. & & & & 98 & 99 & & & & & \\
\hline Unicaja & & & & & & 100 & & & & \\
\hline
\end{tabular}

Fuente: MERCO www.merco.info

Las razones de la creciente mala imagen se vinculan a la opacidad de sus productos, su negocio y sus prácticas, con la consiguiente insatisfacción y perplejidad de sus clientes, problemas a los que se añaden actividades ilegales y escándalos corporativos, fruto de gestiones irresponsables. Los escándalos que se habían sucedido hasta entonces parecían nimios frente a la magnitud mostrada. Tras diez años de crecimiento medio del crédito a tasas superiores al 15\% anual (cuando la economía lo hacía en torno al 3\%), tras alardear de beneficios récord que justificaban remuneraciones e indemnizaciones desproporcionadas a los "gestores estrella" y tras vanagloriarse de tener los mayores niveles de solvencia, se mostró un monstruoso desequilibrio patrimonial, un colapso absoluto de la actividad crediticia y la urgencia de un socorro financiero público, sin que ninguno de los responsables respondiera por su culpa o su negligencia.

Este descrédito está vinculado en gran medida al olvido del elemento ético, entendido en su sentido más primigenio de "ethos", como conducta recta, hábito o modo de ser encaminado a la búsqueda del bien general ${ }^{3}$. Se trata de ir más allá del cumplimiento de las exigencias legales, para integrar un conjunto de bienes morales como la honestidad, la confianza, el respeto y la justicia en las políticas, prácticas y en la toma de decisiones empresariales a todos sus niveles ${ }^{4}$.

\footnotetext{
${ }^{3}$ Rafael Andreu y Josep M. Rosanas se preguntaban en el periódico La Vanguardia de 9/10/2012, “iHemos aprendido algo?". En el artículo citaban un estudio de un bufete de abogados que entrevistó a 500 altos ejecutivos de empresas norteamericanas y británicas. Los resultados son elocuentes: una cuarta parte de los entrevistados veía "normal" las conductas poco éticas en su entorno; la misma proporción opinaba que en servicios financieros "no hay más remedio que comportarse de manera ilegal o incluso poco ética si se quiere tener éxito".

${ }^{4}$ El Instituto de Estudios Bursátiles (IEB) junto con el World Savings Banks Institute (WSBI) y la London School of Economics (LSE) elaboró en septiembre de 2012 un decálogo de banca responsable, con el que homogeneizar los criterios y actuaciones acordes con esa exigencia del mercado. En coherencia el IEB va a poner en marcha a principios de 2013 el Executive Master in Responsible Banking, dirigido por Jorge Medina, en
}

REVESCO No 109 - MONOGRÁFICO: La financiación complementaria y la respuesta de

la economía social: la situación del "des-crédito" bajo la crisis financiera -

ISSN: $1885-8031$ - www.ucm.es/info/revesco 


\section{EL COMPONENTE ÉTICO EN LAS COOPERATIVAS DE CRÉDITO}

Desde los orígenes del movimiento cooperativo se ha hecho especial hincapié en el componente social, democrático, participativo y solidario. Esta voluntad ha sido manifiesta tanto en su gestación, cuando predominaba la dimensión utópica, como en la expansión bajo el predominio de la dimensión ético-religiosa, así como en la actualidad, en la que ha alcanzado cierto grado de homogeneidad operativa con las empresas de corte capitalista. El componente ético de las cooperativas, en este caso las de crédito, se puede analizar a través de tres grandes vectores: desde la herencia de sus orígenes, desde su estructura de gobierno y desde sus objetivos y medios.

Por lo que se refiere a sus orígenes no hay que olvidar que las cooperativas nacieron como respuesta a determinados fallos del sistema económico, social, legal o político, por cuanto el statu quo excluía a determinados actores que tuvieron que recurrir a soluciones solidarias. Tal fue el caso a finales del siglo XIX de los pequeños y medianos agricultores y artesanos, necesitados de crédito, cuya demanda no era satisfecha por las grandes instituciones lucrativas capitalistas. En este sentido, las cooperativas de crédito continúan hoy en día desempeñando un papel clave en la inclusión financiera de determinados colectivos desatendidos, especialmente en áreas rurales.

En cuanto a la estructura de gobierno, ésta viene determinada por las especiales relaciones que, desde la creación de estas entidades, se establecen entre los socios y la propia cooperativa. La unión de los socios se forja por la necesidad de abordar un objetivo común bajo el principio de solidaridad, lo que determina una estrecha relación e identidad entre empresa y usuario, y entre ambos y el resto de la sociedad. Si bien el mayor tamaño alcanzado y la evolución del negocio financiero han debilitado esta proximidad, todavía se aprecia una vinculación con el medio en el que se desenvuelven las cooperativas y siguen vigentes principios que determinan un gobierno democrático y una potencial capacidad de control por parte de los socios.

los que se abordan cuestiones de gobierno, inversión responsable, respeto al medio ambiente, contribución a la comunidad, relaciones con empleados o la estabilidad financiera (Expansión, 28/09/2012).

REVESCO No 109 - MONOGRÁFICO: La financiación complementaria y la respuesta de la economía social: la situación del "des-crédito" bajo la crisis financiera -

ISSN: 1885-8031 - www.ucm.es/info/revesco 
Finalmente, por lo que se refiere al tercer vector citado, la cooperativa, por definición, no busca como objetivo último la maximización de los beneficios para retribuir el capital, sino proporcionar determinados servicios a los socios. Por tanto, el beneficio es un medio, y no un fin, para satisfacer las necesidades de quienes se integran en la cooperativa. En consecuencia, el objetivo social se presenta más amplio y difuso, menos mensurable y, por tanto, menos susceptible de constituir objeto de retribución a los directivos.

De hecho, los principios y valores de las cooperativas, desde sus formulaciones originarias de los Pioneros de Rochdale, han ido adaptándose a las circunstancias de un mundo cambiante, pero manteniendo unos elementos que marcan un contenido con unas consecuencias éticas claras.

Estos elementos han sido vistos por algunos como una limitación a la libre concurrencia en los mercados eminentemente capitalistas y, por tanto, una debilidad para su posición competitiva, hasta el punto de dudar de la viabilidad de las empresas cooperativas regidas estrictamente bajo sus principios. La realidad, no obstante, ha mostrado una gran paradoja: aquellas debilidades atribuidas a las cooperativas de crédito por su naturaleza (Palomo et. al, 2010) han sido precisamente las que las han aislado de la exuberancia irracional del crédito y de los efectos devastadores de la crisis.

Tabla 2. Consecuencias y efectos ante la crisis de los Principios de la Alianza Cooperativa Internacional

\begin{tabular}{|l|l|l|l|}
\hline $\begin{array}{l}\text { Principios de la } \\
\text { ACI }\end{array}$ & $\begin{array}{l}\text { Consecuencias } \\
\text { generales }\end{array}$ & $\begin{array}{l}\text { Consecuencias } \\
\text { económicas }\end{array}$ & Efectos ante la crisis \\
\hline $\begin{array}{l}\text { Adhesión } \\
\text { voluntaria y } \\
\text { abierta }\end{array}$ & $\begin{array}{l}\text { Ausencia de } \\
\text { discriminación y énfasis } \\
\text { en la inclusión } \\
\text { financiera }\end{array}$ & $\begin{array}{l}\text { Banca al por menor } \\
\text { presente en el medio rural. } \\
\text { Elevados costes } \\
\text { operativos. Problemas de } \\
\text { eficiencia. }\end{array}$ & $\begin{array}{l}\text { Menor asimetría informativa } \\
\text { por la capacidad de } \\
\text { controlar a los clientes. } \\
\text { Menor morosidad }\end{array}$ \\
\hline $\begin{array}{l}\text { Gestión } \\
\text { democrática } \\
\text { por parte de los } \\
\text { socios }\end{array}$ & $\begin{array}{l}\text { Responsabilidad de los } \\
\text { representantes ante los } \\
\text { socios en Asamblea } \\
\text { democrática }\end{array}$ & $\begin{array}{l}\text { Fragmentación del capital. } \\
\text { Resistencia a la } \\
\text { concentración. } \\
\text { Reducido tamaño. } \\
\text { Transparencia informativa }\end{array}$ & $\begin{array}{l}\text { Oferta comercial limitada. } \\
\text { Menor sofisticación } \\
\text { financiera. } \\
\text { Incapacidad de afrontar } \\
\text { operaciones de gran calado. }\end{array}$ \\
\hline $\begin{array}{l}\text { Participación } \\
\text { económica de } \\
\text { los socios }\end{array}$ & $\begin{array}{l}\text { Papel subsidiario del } \\
\text { capital. Ausencia de } \\
\text { lucro. }\end{array}$ & $\begin{array}{l}\text { Dificultad de financiarse } \\
\text { en mercados de capitales } \\
\text { mayoristas. }\end{array}$ & $\begin{array}{l}\text { Recurso a los depósitos } \\
\text { tradicionales y aislamiento } \\
\text { de los problemas de } \\
\text { liquidez. }\end{array}$ \\
\hline $\begin{array}{l}\text { Autonomía e } \\
\text { independencia }\end{array}$ & $\begin{array}{l}\text { No sujeción a intereses } \\
\text { de los poderes públicos } \\
\text { o capitalistas }\end{array}$ & $\begin{array}{l}\text { Menor participación en } \\
\text { macroproyectos públicos. } \\
\text { Menor visibilidad. }\end{array}$ & $\begin{array}{l}\text { Relativo aislamiento de } \\
\text { grandes operaciones } \\
\text { fallidas. Comportamiento } \\
\text { menos oportunista y más } \\
\text { prudente. }\end{array}$ \\
\hline
\end{tabular}

REVESCO Nº 109 - MONOGRÁFICO: La financiación complementaria y la respuesta de la economía social: la situación del "des-crédito" bajo la crisis financiera -

ISSN: 1885-8031 - www.ucm.es/info/revesco 


\begin{tabular}{|l|l|l|l|}
\hline & & & $\begin{array}{l}\text { Menor pérdida de } \\
\text { reputación }\end{array}$ \\
\hline $\begin{array}{l}\text { Educación, } \\
\text { formación e } \\
\text { información }\end{array}$ & $\begin{array}{l}\text { Regla de oro: } \\
\text { capacitación técnica y } \\
\text { cooperativa a directivos, } \\
\text { empleados, socios y } \\
\text { sociedad. }\end{array}$ & $\begin{array}{l}\text { Directivos procedentes de } \\
\text { promoción interna y } \\
\text { políticas de retribución } \\
\text { igualitarias. Dificultad de } \\
\text { mantener gestores eficaces. }\end{array}$ & $\begin{array}{l}\text { Aislamiento de escándalos } \\
\text { por retribuciones. } \\
\text { Relativa autonomía en la } \\
\text { gestión de los directivos. }\end{array}$ \\
\hline $\begin{array}{l}\text { Cooperación } \\
\text { entre } \\
\text { cooperativas }\end{array}$ & $\begin{array}{l}\text { Incentivo a consolidar } \\
\text { estructuras nacionales, } \\
\text { regionales e } \\
\text { internacionales }\end{array}$ & $\begin{array}{l}\text { Solidaridad entre } \\
\text { cooperativas. } \\
\text { Respeto a los ámbitos } \\
\text { territoriales. }\end{array}$ & $\begin{array}{l}\text { Mantenimiento en ámbitos } \\
\text { originarios y ausencia de } \\
\text { crecimiento agresivo en } \\
\text { otros territorios. }\end{array}$ \\
\hline $\begin{array}{l}\text { Interés por la } \\
\text { comunidad }\end{array}$ & $\begin{array}{l}\text { Búsqueda del desarrollo } \\
\text { sostenible. Arraigo e } \\
\text { identificación con su } \\
\text { comunidad y el medio. }\end{array}$ & $\begin{array}{l}\text { Identificación y arraigo } \\
\text { con el medio rural. }\end{array}$ & $\begin{array}{l}\text { Mayor vinculación con la } \\
\text { economía productiva y no } \\
\text { tanto especulativa. }\end{array}$ \\
\hline
\end{tabular}

Fuente: Elaboración propia

Por mantener un cierto paralelismo con los tres vectores que determinan el componente ético, se puede hablar de tres debilidades atribuidas tradicional y reiteradamente a las cooperativas de crédito y que, en cierta medida, les ha permitido salir airosas de las turbulencias de la crisis: la eficiencia, el tamaño y el gobierno.

En primer lugar, por sus orígenes y su desarrollo, las cooperativas de crédito han desarrollado una banca de proximidad, con una presencia destacada en el medio rural. Este fenómeno ha generado un relativamente elevado número de oficinas en relación a su negocio, lo que provoca elevados costes operativos y ratios de eficiencia poco satisfactorios. A fin de cuentas, las cooperativas de crédito han mantenido una firme vocación de inclusión financiera (Chaves y Soler, 2004), no solo por su atención a colectivos desatendidos por la gran banca sino también por su presencia en lugares que no alcanzan el umbral de rentabilidad económica. En consecuencia, no han podido sostener la carrera de la eficiencia emprendida por bancos y cajas de ahorros. Para ellos la eficiencia se convirtió en el principal criterio de valoración, aumentándola no solo racionalizando el número de sucursales, sino también incrementando el apalancamiento, recurriendo a financiación en los grandes mercados o haciendo uso creciente de sofisticados productos financieros ${ }^{5}$. En cambio, las cooperativas tan

\footnotetext{
${ }^{5}$ Recientemente se ha cuestionado el papel de inclusión financiera de las entidades no lucrativas. De hecho, la banca capitalista amplió en los primeros años del siglo XXI el espectro de sus prestatarios, pero de una manera poco "saludable", como se puso de manifiesto con las hipotecas sub-prime de los Estados Unidos. De hecho, la inclusión se planteó de forma coyuntural, en un intento de llevar más allá de los límites razonables los beneficios del excesivo apalancamiento, hacia aquellos a los que se les ha aplicado el acrónimo ninja (no income, no job, no assets). Frente a esta inclusión lucrativa se opone la inclusión desde dentro, es decir, mediante la creación de mecanismos solidarios por parte de los excluidos, como ocurrió con las cooperativas en sus orígenes del siglo XIX o como vienen haciendo las instituciones de micro-finanzas.
}

REVESCO Nº 109 - MONOGRÁFICO: La financiación complementaria y la respuesta de la economía social: la situación del "des-crédito" bajo la crisis financiera -

ISSN: 1885-8031 - www.ucm.es/info/revesco 
solo podían aspirar a mejorar ese indicador, sin renunciar al mantenimiento del servicio a sus socios, lo que dificultó la expansión desmesurada del crédito y sus consecuencias.

La segunda debilidad atribuida constantemente a las cooperativas de crédito ha sido su tamaño, lo que ha lastrado la diversidad de productos ofrecidos, la consiguiente rentabilidad potencial, así como la diversificación sectorial y geográfica de su actividad financiera. En consecuencia, la capacidad de llevar a cabo políticas de expansión ambiciosas queda mermada. De hecho, muchas cajas de ahorros españolas se sirvieron de la palanca del crédito inmobiliario para implantarse fuera de sus lugares de origen, con agresivas campañas que contribuyeron a multiplicar el riesgo, financiándose en los mercados interbancarios o mediante títulos hipotecarios, lo que a la postre acentuaría sus problemas. Igualmente, el reducido tamaño dificultaba a las cooperativas el crecimiento del crédito por encima del aumento de sus fuentes de financiación tradicionales, en especial los depósitos de los sectores residentes, debido a la dificultad de acceso a los recursos mayoristas.

La tercera debilidad, destacada desde los primeros estudiosos del cooperativismo, es la dificultad de retener los gestores más eficientes, debido a la tradicional política de retribuciones relativamente igualitaria y a recurrir mayoritariamente a profesionales formados en la propia entidad. De este modo se evitó la tentación de fijar y obsesionarse por objetivos aparentemente a largo plazo, pero que se miden a corto plazo, a los que se vinculan remuneraciones desproporcionadas. Por otra parte, los problemas de agencia parecen haber sido en general poco conflictivos, disfrutando los directivos de una cómoda autonomía en la gestión.

A continuación se presentan algunas lecciones (cuadro 1), a "priori" simples, que nos ha dado la crisis relacionadas con algunos aspectos propios de las cooperativas de crédito, y cuyas características intrínsecas de las mismas han sido su salvaguarda.

Cuadro 1. Doce lecciones simples de la crisis para la banca social y cooperativa

\section{Relacionadas con el tamaño}

Lección $1^{a}$. No te obsesiones por crecer, todo tiene su tiempo. La obsesión multiplicadora de las finanzas ha sido una de las protagonistas del largo período en el que se gestó la actual crisis. Muchos gestores "vendieron" su éxito inflando de forma desmesurada los balances, y participando de una retroalimentación positiva que parecía no tener fin, sucumbiendo a la atracción del dinero fácil y rápido, como el generado durante el boom de los 2000. En esta situación, la metáfora médica es significativa: cuando las células crecen demasiado rápido no

REVESCO No 109 - MONOGRÁFICO: La financiación complementaria y la respuesta de la economía social: la situación del "des-crédito" bajo la crisis financiera -

ISSN: 1885-8031 - www.ucm.es/info/revesco 
suele ser síntoma de nada bueno, por lo que, cuanto menos, conviene extremar la prudencia.

Lección $2^{a}$. Medita bien antes de imitar a los grandes. De forma más evidente entre las cajas de ahorros, las pequeñas y medianas entidades trataron de imitar a las grandes, desarrollando campañas de crecimiento fuera de sus territorios y consolidando voluminosas carteras de participadas, empujadas por la ambición de sus directivos y el apoyo de unos políticos que los alentaban como forma de ampliar su red de influencia. Las entidades pequeñas sucumbieron al comportamiento de rebaño (herd behaviour) convencidas de que, como ya resaltara Keynes, para su reputación es preferible equivocarse convencionalmente que triunfar fuera de la norma.

Lección $3^{a}$. El tamaño no lo es todo. Vinculado con las lecciones anteriores, los directivos tenían incentivos a imitar el crecimiento de otras sociedades y mostrarlo como reflejo de su éxito. Se ignora con ello máximas fundamentales de la actividad financiera, como la selección adversa o el incentivo perverso, por los que los proyectos y operaciones adicionales generalmente tenderán a incorporar un mayor riesgo y una rentabilidad menos segura.

\section{Relacionadas con la dirección y el gobierno}

Lección $4^{a}$. No metas el zorro en el gallinero. Esta lección era especialmente pertinente para las cajas de ahorros, a pesar de lo cual es válida para cualquier tipo de institución, en concreto las cooperativas de crédito. De hecho, los responsables últimos de las entidades han situado al frente de la gestión a directivos que ignoraban o soslayaban (incluso renegaban abiertamente) los principios y valores de las sociedades a las que se les encomendaba la dirección. La dirección de la actividad, en consecuencia, se orientaba hacia la consecución del inmediato máximo beneficio, confundiendo los fines con los medios.

Lección $5^{a}$. No te seduzcan cosas nuevas que no entiendes. Lo racional, tantas veces repetido en la economía pero al mismo tiempo tan ignorado, es hacer uso de las operaciones que conoces y que, por tanto, eres capaz de valorar adecuadamente. En un contexto de euforia es fácil sucumbir al exceso de confianza ante productos estructurados cuyo riesgo parecía estar diluido o cuanto menos controlado, sobre todo cuando los más grandes y experimentados los manejaban con profusión. El incentivo aumentaba cuando el que ponía a disposición estos productos amenazaba a la entidad que tenía que venderlos con perder el tren de la modernidad y de la posición frente a la competencia.

\section{Relacionadas con objetivos y distribución del excedente}

Lección $\sigma^{a}$. No pagues en función de los resultados inmediatos. Los directivos se postularon como los artífices del crecimiento y, por tanto, acreedores de los beneficios a corto plazo que se acumularon, lo que generó una distribución asimétrica de las rentas ${ }^{6}$. Además, gran parte de ese crecimiento inusitado se debió a la concesión de créditos a clientes sin suficientes garantías $\mathrm{y}$, sobre todo, a proyectos inviables sin fundamento. Con esta explosión del crédito se justificaron las crecientes recompensas enmascaradas bajo la fórmula de bonus, planes de pensiones, premios o indemnizaciones, que desbordaron el límite de lo moralmente aceptable, tras superar con creces los parámetros que habían escandalizado pocos años antes ${ }^{7}$.

Lección $7^{a}$. A la hora de remunerar no olvides que eres una cooperativa. Por tanto, en primer lugar, más que beneficios son excedentes, y, además, éstos no son sólo fruto de la pericia de unos directivos, sino también de la acción de los empleados y de los socios-clientes a los que

\footnotetext{
${ }^{6}$ El periódico Financial Times de 09/01/2011 recogía la remuneración de los jefes ejecutivos en las empresas norteamericanas en relación al salario medio de sus respectivas empresas. Dicha relación pasó de 70 en 1990 , a 299 en 2000, para alcanzar 325 en 2010.

${ }^{7}$ Incluso entre los círculos empresariales españoles se acuñó el término "Corcóstegui" como unidad de medida oficiosa para las retribuciones de los dirigentes bancarios, cuyo nombre es el de un antiguo consejero del Banco Santander que en 2002, al dejar la entidad, cobró una pensión de 107 millones de euros.
}

REVESCO No 109 - MONOGRÁFICO: La financiación complementaria y la respuesta de

la economía social: la situación del "des-crédito" bajo la crisis financiera -

ISSN: 1885-8031 - www.ucm.es/info/revesco 
de alguna manera se les ha de hacer partícipes. La relativa horizontalidad de las retribuciones en las cooperativas ha permitido eludir escándalos lamentablemente frecuentes. A fin de cuentas, el objetivo de la sociedad cooperativa no es tanto la maximización de los excedentes, sino prestar los servicios que requieren los socios en las mejores condiciones posibles.

Lección $8^{a}$. No identifiques riesgo y beneficio. Para la empresa capitalista el beneficio, motor de la actividad, es la recompensa por el riesgo asumido. Los bonus e incentivos para los gestores son la forma de hacerles partícipes del éxito al apostar por la opción ganadora. La idea, llevada al extremo, es la que ha hecho interpretar el mercado como un casino. Por el contrario, las cooperativas parten de la mítica e idílica noción de los pioneros de Rochdale, por la que el beneficio es injusto, al ser consecuencia de aplicar a los socios-usuarios precios excesivos, de ahí la tendencia de devolver parte de esos excedentes a quienes contribuyeron a generarlos.

\section{Relacionadas con la gestión de la cooperativa}

Lección $9^{a}$. Valora el capital pero sin obsesionarte. El estallido de la crisis financiera y el deterioro de los activos bancarios pusieron de manifiesto la inadecuación de los niveles de capital. En esta cuestión conviene recordar a Voltaire, quien sostenía que la auténtica forma de alcanzar la felicidad era evitando perseguirla. Algo parecido se aprecia en las entidades de crédito, y en las cooperativas de crédito en particular, por cuanto aquellas que menos se han preocupado en obtener capital son las que precisamente suelen disponer de mayor holgura de recursos propios gracias a su política de consolidación de reservas.

Lección $10^{a}$. Si entras en el casino hazlo solo con lo que te sobre, no con lo que te haga falta en un futuro. La metáfora del casino para referirse al capitalismo desenfrenado de la década anterior a la crisis ha sido sintomáticamente utilizada por muchos de los economistas actuales. Sin duda alguna la llamada de la cornucopia ha confundido a quienes en vez de negocio buscaban fortuna rápida, lo que ha sido una tentación a la que han sucumbido no solo individuos que emprendieron su particular huida hacia delante, sino, sorprendentemente, instituciones con una dilatada experiencia.

Lección $11^{a}$. No pongas todos los huevos en la misma cesta. Las expectativas de crecimiento sin límites de los activos inmobiliarios generó el espejismo de una burbuja que sorprendentemente duró más de lo deseable. El problema no era entrar en su dinámica, sino apostar decididamente obviando los principios elementales de diversificación.

Lección $12^{a}$. La virtud en la gestión empresarial consiste en combinar eficiencia y valores. De hecho, la crisis no es exclusivamente económica, sino también de una sociedad en la que los principios éticos se han ido debilitando paulatinamente. La voracidad de la "mano invisible", que con su codicia debía extender el progreso, requiere de una "ley invisible" que la conduzca por el camino virtuoso (K. Jackson, 2012). A fin de cuentas, como enseña la cultura popular "la avaricia ha roto el saco".

\section{Fuente: Elaboración propia}

De hecho, a mediados de la primera década del siglo XXI las cooperativas de crédito constataban con preocupación cómo su cuota de mercado dejaba de crecer, incluso retrocedía. Los embates iniciales del cataclismo les sorprendió, como a todos, sacando a relucir errores de gestión. No obstante, la avalancha de noticias sobre la delicada situación patrimonial dejaba de lado a unas entidades, las cooperativas, que llevaban a cabo una consolidación 
silenciosa. La prudencia y la discreción las ha aislado del deterioro de imagen que ha sufrido el conjunto del sistema financiero.

Por otra parte, el descrédito ha generado una demanda social de entidades responsables, tanto desde el lado de los excluidos del crédito como desde aquellos ahorradores sensibilizados con el destino de su dinero.

\section{MICROFINANZAS Y BANCA SOCIAL}

A mediados de los años setenta surge una nueva forma de hacer banca impulsada por iniciativas de la sociedad civil (ONG, fundaciones y cooperativas) en los países del llamado Tercer Mundo, con la que se pretende escapar del círculo vicioso de la pobreza por medio de créditos de pequeña cuantía, pero de gran impacto para los receptores.

Su aparición se produce en distintas regiones pobres del planeta: en América Latina con ACCION Internacional, en la India con el Banco Asociación de Autoempleo de Mujeres, el Bank Rakayat de Indonesia y en Bangla Desh el Grameen Bank, que constituirá el paradigma del microcrédito. Tras una década de consolidación, en los años noventa el término "microcrédito" es sustituido por otro más amplio, "microfinanzas", que va más allá de los servicios bancarios típicos de crédito y ahorro, para englobar además otros servicios, como los seguros o las transferencias de dinero.

Los éxitos alcanzados tuvieron un extraordinario impacto, fruto del cual en 1997 se convocó la Cumbre Internacional de las Microfinanzas en Washington. A partir de este momento los proyectos se multiplican difundiéndose una euforia que tendrá como colofón la concesión del Premio Nobel de la Paz en 2006 a Muhammad Yunus, impulsor del microcrédito que se valora como una herramienta para reducir la pobreza mediante la inclusión financiera de los más necesitados. Si hasta entonces las microfinanzas habían sido impulsadas por organizaciones no lucrativas, a partir del cambio de siglo son parcialmente ofrecidas también por la banca comercial, fenómeno que Yunus ya destacó mostrando sus reticencias en el discurso de recepción del Premio Nobel. Paralelamente, algunas instituciones de microfinanzas abandonaron su naturaleza original para abrazar formas mercantiles. El caso

REVESCO No 109 - MONOGRÁFICO: La financiación complementaria y la respuesta de la economía social: la situación del "des-crédito" bajo la crisis financiera -

ISSN: 1885-8031 - www.ucm.es/info/revesco 
más destacado fue el mexicano Banco Compartimos, surgido a partir de una ONG nutrida de subsidios y ayudas para la lucha contra la pobreza, que en 2007 salió a Bolsa.

A partir de entonces se asiste a un relativo agotamiento de los mitos del emprendedor pobre y de la palanca del crédito, produciéndose las primeras decepciones y distensiones. Reflejo de ello fueron las agrias desavenencias entre Yunus y la primera ministra bengalí Sheik Hasina Wazed en febrero de 2011, que terminó con el cese de aquél al frente del Grameen Bank. A pesar de ello, las microfinanzas han supuesto una auténtica revolución, por cuanto ha impulsado un cambio radical en la metodología de los préstamos (García y Díaz, 2011), ha ampliado el espectro de los beneficiarios con una especial atención hacia la gente sin recursos y hacia las mujeres, supliendo la ausencia de garantías colaterales con la solidaridad de los grupos, y ha alterado las prioridades financieras, primando el desarrollo autosostenido de las colectividades en las que funciona.

En consecuencia la microfinanza se entiende como la provisión a pequeña escala de servicios financieros a personas con dificultades de acceso a los servicios bancarios, cuyos rasgos definitorios son los siguientes (Karlan \& Goldberg, 2011, 54-55):

- Transacciones de pequeño importe

- Préstamos para actividades de emprendimiento

- Sin exigencia de garantías colaterales

- Solidaridad dentro del grupo. Cuando un prestatario no puede devolver el préstamo los otros miembros del grupo son requeridos contractualmente.

- Preferencia por clientes pobres

- Preferencia por mujeres

- Procesos de aplicación simple

- Preferencia por comunidades excluidas financieramente

- Aplicación de tipos de interés de mercado.

Un análisis de la gestación de este tipo de instituciones permite apreciar evidentes paralelismos con la emergencia de las cooperativas de crédito un siglo antes. De hecho, la garantía solidaria del microcrédito tiene semejanzas con la responsabilidad ilimitada de las 
primeras cooperativas Raiffeisen. Asimismo, la proximidad con el prestatario facilita el control de la solvencia del mismo por la entidad. También presenta similitud la vinculación con la actividad productiva de los socios que se integran voluntariamente en la institución, buscando la cooperación con instrumentos semejantes. Ambas emergen como alternativa al racionamiento del crédito por parte de las sociedades bancarias lucrativas y presentan una gran variedad de modelos en función de las distintas situaciones regionales. Finalmente, tanto cooperativas como instituciones de microfinanzas tienen una vocación de responsabilidad, gobierno y sostenibilidad coherentes con determinados valores éticos.

Las instituciones de microfinanzas y las cooperativas de crédito comparten gran parte de las motivaciones que movieron a la creación de la llamada "banca social" (Rizkallah y Buendía, 2011; Castro y Romero, 2011). Así, "banca social” es un término que presenta multitud de facetas y que engloba aquellas entidades que persiguen un impacto social, bien a partir de la lucha contra la pobreza y la exclusión, bien favoreciendo el desarrollo sostenido y la preservación del medio ambiente, respetando valores éticos ${ }^{8}$ y que están guiadas por tres principios en su gestión: transparencia, comunicación y participación.

Por tanto, se suele distinguir dos tipos de "banca social". Por una parte, los bancos éticos, presentes normalmente en países desarrollados, que representan una alternativa para los clientes que demandan mayor responsabilidad y la seguridad de que su ahorro tiene un destino coherente con determinadas prioridades. Por otra, bancos que persiguen la reducción de la pobreza, frecuentes en países del llamado Tercer Mundo, vinculados frecuentemente a las instituciones del microcrédito (tabla 3).

Tabla 3. Principales bancos sociales

\begin{tabular}{|l|l|l|}
\hline \multicolumn{2}{|c|}{ Bancos éticos } \\
\hline 1974 & $\begin{array}{l}\text { GLS Gemeinschaftsbank, Alemania } \\
\text { www.gls.de } \\
\text { En 2003 adquirió el banco medioambiental Ökobank }\end{array}$ & $\begin{array}{l}\text { Activos (2008), 34 } \\
\text { Benef. (2008), 0,2 }\end{array}$ \\
\hline 1980 & $\begin{array}{l}\text { Triodos Bank, Holanda } \\
\text { www.triodos.com }\end{array}$ & $\begin{array}{l}\text { Activos (2008), 2.700 } \\
\text { Benef. (2008), 11,5 }\end{array}$ \\
\hline 1982 & $\begin{array}{l}\text { Mercar Bank, Dinamarca } \\
\text { www.merkur.dk }\end{array}$ & $\begin{array}{l}\text { Activos (2008), 184 } \\
\text { Benef. (2008), 0,8 }\end{array}$ \\
\hline
\end{tabular}

\footnotetext{
${ }^{8}$ Los valores de la "banca social" aparecen recogidos en la Global Alliance for Banking Values (www.gabv.org) y el Institute for Social Banking (www.social-banking.org).
}

REVESCO No 109 - MONOGRÁFICO: La financiación complementaria y la respuesta de la economía social: la situación del "des-crédito" bajo la crisis financiera -

ISSN: $1885-8031$ - www.ucm.es/info/revesco 


\begin{tabular}{|l|l|l|}
\hline 1984 & Freie Gemeinschaftsbank BLC, Suiza & \\
\hline 1987 & $\begin{array}{l}\text { Alternative Bank Schweiz (ABS) } \\
\text { www.abs.ch }\end{array}$ & $\begin{array}{l}\text { Activos (2009), 650 } \\
\text { Benef. (2008) 0.63 }\end{array}$ \\
\hline 1988 & $\begin{array}{l}\text { Hermes, Austria } \\
\text { www.hermes-oesterreich.at }\end{array}$ & $\begin{array}{l}\text { Activos (2008), 8,1 } \\
\text { Benef. (2008) 0.06 }\end{array}$ \\
\hline 1989 & $\begin{array}{l}\text { Société Financiere de la NEF, Francia (cooperativa) } \\
\text { www.lanef.com }\end{array}$ & $\begin{array}{l}\text { Activos (2009), 68 } \\
\text { Benef. }\end{array}$ \\
\hline 1994 & $\begin{array}{l}\text { Banca Popolare Etica, Italia } \\
\text { www.bancaetica.com }\end{array}$ & $\begin{array}{l}\text { Activos (2008), 612 } \\
\text { Benef. (2008) 1.2 }\end{array}$ \\
\hline 1997 & $\begin{array}{l}\text { Cultura Sparebank, Noruega } \\
\text { www.cultura.no }\end{array}$ & $\begin{array}{l}\text { Activos (2008), 46 } \\
\text { Benef. (2008) 0,24 }\end{array}$ \\
\hline 1998 & $\begin{array}{l}\text { Ekobanken, Suecia } \\
\text { www.ekobanken.se }\end{array}$ & $\begin{array}{l}\text { Activos (2008), 34 } \\
\text { Benef. (2008) 0.07 }\end{array}$ \\
\hline 2001 & $\begin{array}{l}\text { Charity Bank, Reino Unido } \\
\text { www.charitybank.org }\end{array}$ & $\begin{array}{l}\text { Activos (2008), 68 } \\
\text { Benef. (2008) -1,67 }\end{array}$ \\
\hline & $\begin{array}{l}\text { New Resource Bank, Estados Unidos } \\
\text { www.newresourcebank.com }\end{array}$ & $\begin{array}{l}\text { Activos (2009), 139 } \\
\text { Benef. (2008) 10.6 }\end{array}$ \\
\hline \multicolumn{2}{|c|}{ Bancos para reducción de la pobreza } & \\
\hline 1972 & $\begin{array}{l}\text { BRAC, Bangla Desh } \\
\text { www.brac.net }\end{array}$ & $\begin{array}{l}\text { Activos (2008), 860 } \\
\text { Benef. (2008) 11.6 }\end{array}$ \\
\hline & $\begin{array}{l}\text { Banco del Éxito, Nicaragua } \\
\text { www.banex.com.ni }\end{array}$ & $\begin{array}{l}\text { Activos (2008), 147 } \\
\text { Benef. (2008) } 2,3\end{array}$ \\
\hline & $\begin{array}{l}\text { Shore Bank, Estados Unidos } \\
\text { www.shorebankcorp.com }\end{array}$ & $\begin{array}{l}\text { Activos (2008), 2,2 } \\
\text { Benef. (2008) 1,8 }\end{array}$ \\
\hline 1998 & $\begin{array}{l}\text { Mi Banco, Perú } \\
\text { www.mibanco.com.pe }\end{array}$ & $\begin{array}{l}\text { Activos (2009), 902 } \\
\text { Benef. (2008) 9,7 }\end{array}$ \\
\hline 2001 & $\begin{array}{l}\text { XAC Bank, Mongolia } \\
\text { www.xacbank.mn }\end{array}$ & $\begin{array}{l}\text { Activos (2008), 134 } \\
\text { Benef. (2008) 2.65 }\end{array}$ \\
\hline
\end{tabular}

Fuente: Elaboración propia y De Clerck (2009). Año de fundación. Cifras en millones de euros

La "banca social" presenta grandes similitudes con las cooperativas de crédito por lo que se refiere a su origen y, a nivel operativo, a las amenazas/oportunidades de su negocio. Las amenazas se refieren fundamentalmente a su tamaño y la repercusión que ello representa: profesionalidad de directivos, innovación, competencia, no prioridad a la maximización de los beneficios, etc. En definitiva, se achaca que su sistema de valores puede entorpecer la libre concurrencia con las instituciones capitalistas.

De hecho, se trata de entidades relativamente pequeñas. El mayor, Triodos Bank, tiene cierta presencia internacional (Holanda, Reino Unido, España, Bélgica, Alemania). Dentro de los bancos para el desarrollo, el BRAC bengalí también está presente en varios países africanos. 
En España al igual que sus homólogos europeos se ha incrementando el interés por las finanzas éticas. Actualmente se evidencia una reorientación solidaria de una parte de la oferta de servicios financieros, que prioriza el compromiso social de su actividad sin descuidar, por ello, la viabilidad económica (Cabaleiro y Rodríguez, 2008).

A continuación se presenta (tabla 4) una relación de los principales actores de las finanzas éticas que optan por diferentes formas jurídicas (bancos o cooperativas de créditos), la finalidad que persiguen y el producto básico que ofrecen, así como el montante global de volúmenes gestionados, saldo de créditos y depósitos (tabla 5).

REVESCO No 109 - MONOGRÁFICO: La financiación complementaria y la respuesta de la economía social: la situación del "des-crédito" bajo la crisis financiera -

ISSN: 1885-8031 - www.ucm.es/info/revesco 
Tabla 4. Principales actores de las finanzas éticas en España

\begin{tabular}{|c|c|c|c|}
\hline Denominación & Objetivo & Producto básico & Web contacto \\
\hline Triodos bank & $\begin{array}{l}\text { Financiar empresas e iniciativas que, además } \\
\text { de ser rentables, mejoren la calidad de vida } \\
\text { de las personas y respeten la naturaleza, más } \\
\text { ahorro responsable }\end{array}$ & $\begin{array}{l}\text { Amplia oferta bancaria para particulares, } \\
\text { empresas e instituciones }\end{array}$ & http://www.triodos.com \\
\hline Fiare & $\begin{array}{l}\text { Financiar actividades económicas con } \\
\text { impacto social positivo más ahorro } \\
\text { responsable }\end{array}$ & $\begin{array}{l}\text { Amplia oferta bancaria para entidades de } \\
\text { la economía social }\end{array}$ & http://www.proyectofiare.com \\
\hline Coop 57 S.C.C.L. & $\begin{array}{l}\text { Financiar proyectos de cooperativas con } \\
\text { impacto social positivo más ahorro } \\
\text { responsable }\end{array}$ & $\begin{array}{l}\text { Financiación de proyectos, inversiones, } \\
\text { circulante, anticipos de subvenciones e } \\
\text { intercooperación }\end{array}$ & http://www.coop57.coop \\
\hline Oikocredit España & $\begin{array}{l}\text { Financiar proyectos para el desarrollo, } \\
\text { básicamente al tercer mundo }\end{array}$ & $\begin{array}{l}\text { Microcréditos y captación de fondos } \\
\text { (ahorro responsable) }\end{array}$ & http://www.pangea.org/oikocredit \\
\hline $\begin{array}{l}\text { Acció solidaria contra l'atur } \\
\text { (ASCA) }\end{array}$ & $\begin{array}{l}\text { Contribuir a hacer frente al problema de la } \\
\text { desocupación y soporte a los inmigrantes }\end{array}$ & Microcréditos & http://www.pangea.org/accio \\
\hline $\begin{array}{l}\text { Fundació internacional de la dona } \\
\text { emprenedora (FIDEM) }\end{array}$ & $\begin{array}{l}\text { Financiar proyectos empresariales en } \\
\text { condiciones ventajosas, sin necesidad de } \\
\text { aval, y proporcionar el asesoramiento } \\
\text { necesario a las mujeres emprendedoras }\end{array}$ & Microcréditos a mujeres & http://www.fidem.net \\
\hline $\begin{array}{l}\text { Comunidades de Autogestión } \\
\text { financiera (CAF) }\end{array}$ & $\begin{array}{l}\text { Ahorrar y conceder pequeños prestamos } \\
\text { entre los miembros de la comunidad }\end{array}$ & Microcréditos & http://www.comunidadescaf.org \\
\hline Sección de crédito de IDEAS & $\begin{array}{l}\text { Pre-financiar la estructura productiva de } \\
\text { grupos productores del Sur }\end{array}$ & Préstamos solidarios & http://www.ideas.coop \\
\hline $\begin{array}{l}\text { Centro de desarrollo de iniciativas } \\
\text { empresariales MITA }\end{array}$ & $\begin{array}{l}\text { Promoción nuevas empresas entre } \\
\text { inmigrantes y mujeres, y cooperación } \\
\text { internacional }\end{array}$ & $\begin{array}{l}\text { Microcréditos entre } 15.000 \text { y } 25.000 \\
\text { euros }\end{array}$ & http://www.mitaong.org \\
\hline $\begin{array}{l}\text { Asociación para la financiación } \\
\text { solidaria }\end{array}$ & $\begin{array}{l}\text { Fomentar los medios alternativos de } \\
\text { financiación de empresas y proyectos de } \\
\text { economía social solidaria }\end{array}$ & Préstamos solidarios & $\begin{array}{l}\text { http://www.reasnet.com/financiacionso } \\
\text { lidaria }\end{array}$ \\
\hline WWWB España, Banco Mundial & Apoyo a la mejor en la creación de & Microcréditos $(15.000 €)$ y fondo de & http://www.bancomujer.org \\
\hline
\end{tabular}

REVESCO No 109 - MONOGRÁFICO: La financiación complementaria y la respuesta de

la economía social: la situación del "des-crédito" bajo la crisis financiera -

ISSN: 1885-8031 - www.ucm.es/info/revesco 


\begin{tabular}{|c|c|c|c|}
\hline de la Mujer & $\begin{array}{l}\text { empresas: asesoramiento, financiamiento, } \\
\text { formación y comercialización }\end{array}$ & garantía para mujeres inmigrantes & \\
\hline Banca Ética de Badajoz & $\begin{array}{l}\text { Constituir un ahorro responsable con más } \\
\text { interés social que económico, para } \\
\text { compartirlo con las persones excluidas } \\
\text { socialmente }\end{array}$ & $\begin{array}{l}\text { Plan de ahorro } \\
\text { Microcréditos }\end{array}$ & http://www.badajoz.org/bancaetica \\
\hline AIS O Peto & $\begin{array}{l}\text { Promover una forma solidaria de ahorro e } \\
\text { inversión ética mediante microcréditos a } \\
\text { proyectos con impacte social y respetuosos } \\
\text { con la naturaleza }\end{array}$ & Microcréditos hasta 10.000 euros & http://opeto.org/ \\
\hline $\begin{array}{l}\text { Grupos de apoyo a proyectos } \\
\text { (GAP) }\end{array}$ & $\begin{array}{l}\text { Conseguir que la economía esté al servicio } \\
\text { de les persones. }\end{array}$ & $\begin{array}{l}\text { Financiación de proyectos para los socios } \\
\text { del GAP }\end{array}$ & http://www.gap.org.es \\
\hline EnClau & $\begin{array}{l}\text { Promover el desarrollo de nuevas } \\
\text { alternativas de financiación de proyectos y } \\
\text { actividades socialmente responsables } \\
\text { rentables }\end{array}$ & $\begin{array}{l}\text { Libreta solidaria } \\
\text { Depósito solidario } \\
\text { Financiación de proyectos }\end{array}$ & http://www.enclau.org \\
\hline IUNA & Inserción laboral & $\begin{array}{l}\text { Bolsa Alternativa } \\
\text { Financiación de proyectos }\end{array}$ & http://www.iuna.org \\
\hline
\end{tabular}

Fuente: Observatorio de las Finanzas éticas (2012). Barómetro de las Finanzas éticas

REVESCO No 109 - MONOGRÁFICO: La financiación complementaria y la respuesta de la economía social: la situación del "des-crédito" bajo la crisis financiera -

ISSN: 1885-8031 - www.ucm.es/info/revesco 
Tabla 5. Volúmenes gestionados (miles de €) por las finanzas éticas en España

\begin{tabular}{|l|c|c|c|c|c|c|}
\hline & 2005 & 2006 & 2007 & 2008 & 2009 & 2010 \\
\hline Préstamos & 54.126 & 98.059 & 163.388 & 283.895 & 398.928 & 487.242 \\
\hline Depósitos & 32.587 & 79.485 & 133.488 & 203.694 & 303.256 & 373.437 \\
\hline \multicolumn{7}{c}{ Fuente: Elaboración propia a partir de Observatorio finanzas éticas (2012) }
\end{tabular}

Las cifras anteriores muestran un incremento significativo y una demanda social por productos socialmente responsables. El crecimiento interanual de las finanzas éticas ha supuesto en el último año un aumento del 23,14\% de los depósitos y del 22,13\% en los créditos. A nivel global la demanda de crédito se ha multiplicado por 8 en el periodo 20052010, y la de depósitos por 10. A pesar del aumento, la cuota sobre el total de las finanzas del Estado es mínima y no deja de ser simbólica, pues representa un $0,02 \%$ del total de los créditos y depósitos. No obstante si es muy importante observar que en esta situación clave de demanda de financiación (captación de pasivo por las entidades financieras) las finanzas éticas siguen creciendo, aunque los tipos con los que remuneran sus depósitos son inferiores al de otras muchas entidades del sistema bancario.

El interés por este tipo de productos es evidente y son varias las entidades financieras, que no siendo en sus orígenes, ni por su actuación prioritaria o forma jurídica, pertenecientes a la banca ética apuestan por estos productos, comercializándolos y ofreciéndolos en su cartera, como así se desprende de la relación de fondos de Instrumentos Socialmente Responsables (tabla 6) comercializados en España.

Tabla 6. Relación de fondos de ISR gestionados y comercializados en España

\begin{tabular}{|l|l|r|}
\hline \multicolumn{1}{|c|}{ Nombre del Fondo } & \multicolumn{1}{|c|}{ Sociedad Gestora } & \multicolumn{1}{|l|}{$\begin{array}{l}\text { Volumen } \\
\text { gestionado } \\
\text { (miles €) (31- } \\
\text { 12-2008) }\end{array}$} \\
\hline Ahorro Corporación Responsable 30 FI & A.C. Gestión SGIIC, S.A. & 4.802 \\
\hline BBK Solidaria, FI & BBK Gestión & 4.115 \\
\hline BBVA Bolsa Desarrollo Sostenible, FI & BBVA Asset Management & 62.539 \\
\hline $\begin{array}{l}\text { BBVA Extra 5 II Garantizado, FI/BBVA } \\
\text { Solidez VFI }\end{array}$ & BBVA Asset Management \\
\hline BNP Paribas Fondo Solidaridad, FI & $\begin{array}{l}\text { BNP Paribas Asset } \\
\text { Management }\end{array}$ \\
\hline $\begin{array}{l}\text { Caja Ingenieros Mundial ISR, FI /Fonengin } \\
\text { FI }\end{array}$ & $\begin{array}{l}\text { Caja Ingenieros Gestión SGIIC, } \\
\text { SA }\end{array}$ \\
\hline
\end{tabular}

REVESCO Nº 109 - MONOGRÁFICO: La financiación complementaria y la respuesta de la economía social: la situación del "des-crédito" bajo la crisis financiera -

ISSN: 1885-8031 - www.ucm.es/info/revesco 


\begin{tabular}{|l|l|r|}
\hline $\begin{array}{l}\text { CAM Fondo Solidaridad, FI/CAM Mixto } \\
\text { Renta Fija, FI }\end{array}$ & 542 \\
\hline $\begin{array}{l}\text { Compromiso Fondo Ético, FI/Gesbeta } \\
\text { Compromiso Fondo Ético FI }\end{array}$ & Gesbeta Meespierson & 8.490 \\
\hline $\begin{array}{l}\text { Foncaixa Cooperación Socialmente } \\
\text { Responsable Europa, FI }\end{array}$ & Invercaixa Gestión SA, SGIIC & 4.363 \\
\hline Foncaixa Privada Fondo Activo Ético, FI & Invercaixa Gestión SA, SGIIC & 8.879 \\
\hline Fondo Solidario Pro Unicef, FI & Gesmadrid, SA, SGIIC & 2.611 \\
\hline Fonpenedès Étic i Solidari, FI & $\begin{array}{l}\text { Caixa Penedes Gestio, SGIIC, } \\
\text { SA }\end{array}$ & 286 \\
\hline $\begin{array}{l}\text { Privado Inversión Socialmente Responsable, } \\
\text { FI }\end{array}$ & & 15.301 \\
\hline Santander Solidario Dividendo Europa FI & $\begin{array}{l}\text { Santander Asset Management, } \\
\text { SA, SGIIC }\end{array}$ & 15.720 \\
\hline Santander Respons. Conservador, FI & $\begin{array}{l}\text { Santander Asset Management, } \\
\text { SA, SGIIC }\end{array}$ & 8.885 \\
\hline Urquijo Cooperación, SICAV & Urquijo Gestión, SAU, SGIIC \\
\hline Urquijo Inversión Ética y Solidaria, FI & $\begin{array}{l}\text { Bansabadell Inversión, SA, } \\
\text { SGIIC }\end{array}$ \\
\hline \multicolumn{1}{|c|}{ Fuente: Observatoio delas Finanzas } \\
\hline
\end{tabular}

Fuente: Observatorio de las Finanzas éticas (2012). Barómetro de las Finanzas éticas

\section{EL PROYECTO FIARE}

Entre las iniciativas de banca ética, ha fraguado en España un proyecto de economía solidaria que pone de manifiesto como las soluciones gestadas por emprendedores sociales ayudan en momentos de crisis. FIARE nace como proyecto en 2001 a través de 52 organizaciones sociales del País Vasco y toma forma en febrero de 2003 con la materialización de las aportaciones fundacionales de sus miembros constituyentes. $\mathrm{Su}$ principal objetivo es canalizar el ahorro de personas y organizaciones al servicio de proyectos de la economía social y solidaria, es decir, proyectos que trabajen para una realidad más justa, participativa e inclusiva. Tiene vocación de transformación social y sus ámbitos de actuación prioritarios son la inserción social de personas en riesgo de exclusión, la cooperación al desarrollo o la sostenibilidad medioambiental.

FIARE es una red de asociaciones que pretende consolidar una sociedad de banca ética alternativa, bajo la fórmula jurídica de cooperativa de crédito. Mientras tanto realiza actividad financiera en España como agente de la Banca Popolare Etica, S. Coop. Para FIARE es importante vincular de la mejor forma posible, los recursos gestionados mediante el ahorro solidario de personas y organizaciones, con las necesidades de financiación de los

REVESCO No 109 - MONOGRÁFICO: La financiación complementaria y la respuesta de la economía social: la situación del "des-crédito" bajo la crisis financiera -

ISSN: 1885-8031 - www.ucm.es/info/revesco 
proyectos que no encuentran respuesta en las entidades financieras tradicionales. Son requisitos para Fiare la financiación exclusiva de proyectos que cumpliendo con una viabilidad económica tengan un impacto social positivo, de modo que el análisis económico financiero previo a todo proyecto empresarial que se desea financiar se complementa con un análisis de su impacto social positivo, valorado por el Comité de Ética (memoria, avales, participación democrática, transparencia, compromiso, buen gobierno, impacto medioambiental, etc.), que verifique si se establece esa correspondencia de principios y valores entre los que aportan los recursos y los que los reciben. FIARE destaca por su transparencia, tanto en las operaciones como en las acciones realizadas. De forma voluntaria publica la información relativa a los productos contratados, depósitos de ahorro y destino.

Actualmente FIARE está integrada por 11 redes territoriales (País Vasco, Cataluña, Navarra, Zona Sur, Centro, Valencia, Castilla-León, Galicia, Canarias, Baleares y, recientemente, Murcia), a las que se suma Coop 57, una cooperativa de servicios financieros creada en Cataluña en 1993. Cada territorio se estructura de forma independiente cumpliendo con los principios generales.

Esta vinculación se materializa con el crecimiento de socios y el de sus aportaciones a capital social. En el presente año se han dado de alta 50 nuevas organizaciones y 748 personas físicas. De hecho el número de socios a cierre de 2011 es de 2.618 (2.314 personas físicas y 304 personas jurídicas), que aportan un capital social de 2.766.278. El crecimiento de capital social ha sido muy destacado en los últimos años pasando de una cifra de 236.050 en 2008 a la actual. El mayor incremento de CS se registró en 2009 que multiplicó por 5 el valor del año anterior, siendo los crecimientos posteriores del 78 y del 30\% en 2010 y 2011. País Vasco, Cataluña y Navarra, son las zonas que aportan casi tres cuartas partes del total del CS del proyecto, y junto con la Zona Sur también del número de socios.

\section{Estado actual del ahorro}

En el periodo 2011-2005 el ahorro depositado en los productos FIARE se ha multiplicado por 10 (tabla 7). El ejercicio 2011 ha sido un año complicado a nivel nacional para las empresas y para las familias que han visto reducida la disponibilidad de ahorro por la REVESCO No 109 - MONOGRÁFICO: La financiación complementaria y la respuesta de la economía social: la situación del "des-crédito" bajo la crisis financiera - 
pérdida de empleo e incobros. Fiare ha incrementado los depósitos en un $15 \%$ y el número de libretas en un $24 \%$ con respecto al ejercicio anterior, una cifra superior al de otras entidades financieras convencionales. La distribución del mismo por tipos de productos se detalla en el tabla 8 .

Tabla 7. Evolución del ahorro (euros) Fiare periodo 2005-2011

\begin{tabular}{|l|c|c|c|c|c|c|c|}
\hline & 2005 & 2006 & 2007 & 2008 & 2009 & 2010 & 2011 \\
\hline Depósitos & 2.848 .522 & 7.434 .587 & 9.584 .032 & 14.082 .585 & 21.115 .268 & 25.076 .489 & 28.961 .297 \\
\hline $\mathrm{N}^{\circ}$ libretas & 62 & 252 & 409 & 639 & 1.073 & 1.400 & 1.733 \\
\hline
\end{tabular}

Fuente: elaboración propia a partir de las Memorias Fiare, varios años. Datos a 31 de diciembre

Tabla 8. Volumen en depósitos (ahorro) Fiare en 2011

\begin{tabular}{|l|r|c|}
\hline Tipo de depósito & Euros $(€)$ & $\mathrm{N}^{\circ}$ libretas \\
\hline Fiare vinculado 24 meses & 9.297 .201 & 893 \\
Fiare vinculado 36 meses & 1.579 .481 & 125 \\
Fiare vinculado 48 meses & 7.025 .963 & 253 \\
TOTAL AHORRO A PLAZO & 17.902 .645 & 1.271 \\
& & \\
Libreta Tesorería & 6.194 .331 & 52 \\
Fiare Disponibilidad & 3.405 .053 & 288 \\
Cuenta Corriente & 1.459 .268 & 122 \\
TOTAL AHORRO A LA VISTA & 11.058 .652 & 462 \\
\multicolumn{1}{|c}{ AHORRO TOTAL } & 28.961 .297 & 1.733 \\
\hline
\end{tabular}

Fuente: Memoria FIARE, 2011. Datos a 31 de diciembre de 2011

Los depósitos en cuentas corrientes contratados principalmente por Internet (así como la disponibilidad del ahorro en cuenta) frente a otro tipo de depósitos que requieren su contratación en oficina, ha propiciado que se produzca un ahorro en este tipo de productos mayor en 2011 que en ejercicios anteriores (actualmente es un 5\% del total del ahorro). El crecimiento en las CCAA sin presencia física de oficinas ha sido notable en estos productos.

Los productos de ahorro habituales consolidan la actividad en País Vasco, Cataluña y Zona Centro-Madrid, mientras que las cuentas corrientes permiten el crecimiento en C.Valenciana y Zona Sur que de otro modo sería imposible. En cuanto a los tipos de productos Fiare oferta un producto especialmente solidario, la libreta Redes, que consiste en un depósito en el que los intereses no los recibe el depositante sino la organización solidaria que éste elija dentro del listado de organizaciones con las que Fiare tiene firmado acuerdo de colaboración con este producto. El destino de estos fondos ha de ser el apoyo mediante el crédito a proyectos orientados a personas que están en riesgo de exclusión social, no siendo REVESCO No 109 - MONOGRÁFICO: La financiación complementaria y la respuesta de la economía social: la situación del "des-crédito" bajo la crisis financiera - 
posible su empleo para otro fin. Estos proyectos son entre otros: Fundación CEPAIM Acción Integral con Migrantes, Fondo de Solidaridad "Paz y Esperanza", Acció Solidària contra l'Atur, Asociación CAF, Comunidades Autofinanzadas, Grupo de Apoyo a Proyectos de Economía al Servicio de las Personas, Solidaridad con el Sur de Sudán, Ideas Comercio Justo, OikoCredit Catalunya, Red de Economía Alternativa y Solidaria. En 2011 fueron 375 libretas las que donaron sus intereses con un importe total de $21.674 €$.

\section{Estado actual del Crédito}

El año 2011 ha seguido la complicada senda de escasa financiación para las entidades de economía social, las pequeñas y medianas empresas, así como los particulares dada la caída del crédito experimentada en los últimos años y que lejos de subsanarse en 2011 ha continuado en fase descendente. Además los retrasos en los pagos y la reducción de la financiación por parte de las Administraciones Públicas con las que habitualmente trabajan las empresas de economía solidaria acrecienta esta necesidad de financiación. Fiare les aporta el capital mediante anticipo en cuenta corriente de subvenciones posteriores, anticipos de contratos con entes públicos, o bien a través de un préstamo.

El crédito aprobado por FIARE para proyectos de emprendimiento social, y economía solidaria, ha ascendido a una cifra de casi 28 millones de euros en 2011, frente a los 19,5 millones aprobados en 2010, siendo el número de operaciones abiertas de 104, superando las 94 de 2010 y 86 de 2009.

Por sectores de actividad (tabla 9), y dadas las características de la entidad objeto de análisis, el principal destino de los créditos es para operaciones de inserción social y de economía solidaria con un 62\% del volumen de las operaciones en 2011, seguido de los valores sociales, 20\%, situándose a continuación el comercio justo y la cooperación internacional, $14 \%$, y siendo más residual la agroecología. El conjunto formado por las actividades solidarias, los valores sociales y la inserción social supone el $80 \%$ del total de las operaciones en el periodo 2009-2010. Los proyectos de emprendimiento encuentran su financiación solidaria más clara en estas entidades (Melián et al., 2010; Melián y Campos, 2010).

REVESCO No 109 - MONOGRÁFICO: La financiación complementaria y la respuesta de la economía social: la situación del "des-crédito" bajo la crisis financiera -

ISSN: 1885-8031 - www.ucm.es/info/revesco 
Tabla 9. Distribución del crédito $(€)$ por sectores

\begin{tabular}{|c|c|c|c|c|c|}
\hline Sectores & Aprobado & $\begin{array}{l}\text { Aprobado } \\
\text { vivo }\end{array}$ & 2009 & 2010 & 2011 \\
\hline Agroecología & 806.000 & 706.000 & 562.928 & 517.094 & 471.040 \\
\hline $\begin{array}{l}\text { Coop. Internacional/ } \\
\text { Comercio Justo }\end{array}$ & 4.161 .000 & 2.948 .000 & 1.254 .662 & 1.853 .807 & 1.917 .490 \\
\hline $\begin{array}{l}\text { Inserción social/ } \\
\text { economía solidaria }\end{array}$ & 15.751 .819 & 14.082 .619 & 6.313 .586 & 7.009 .222 & 8.306 .496 \\
\hline Valores sociales & 7.039 .000 & 6.748 .000 & 559.244 & 1.039 .215 & 2.731 .699 \\
\hline Total & 27.757 .819 & 24.484 .619 & 8.690 .420 & 10.419 .339 & 13.323 .725 \\
\hline
\end{tabular}

Fuente: Memoria Fiare 2011. Datos a 31 de diciembre

Atendiendo al tipo de entidades (tabla 10) que acceden a esta financiación son sobre todo las cooperativas y las asociaciones las que han experimentado un crecimiento significativo, en número de operaciones y en crédito concedido, mientras que la cifra de las fundaciones se ha mantenido. Así las cooperativas han evolucionado de una cuota del $22 \%$ en 2009 al 34\% en 2011 del volumen total de crédito concedido, y las asociaciones han pasado del 10 al 16\%. El incremento de las anteriores hace que aunque los valores globales en cuanto a saldo sean similares a los ejercicios precedentes en las fundaciones, su cuota sobre el volumen total descienda del 36 al 25\%. Por las dificultades de acceso al crédito tradicional, contar con instrumentos financieros adecuados para las empresas del sector de la economía social es condición esencial para el crecimiento económico, que les haga sortear la crisis y que asegure el cumplimiento de la política social a que están llamadas a cumplir las citadas entidades (Bahía, 2011:33).

Tabla 10. Distribución del crédito $(€)$ según tipo de Entidades

\begin{tabular}{|l|r|r|r|r|r|}
\hline Entidades & \multicolumn{1}{|c|}{ Aprobado } & $\begin{array}{c}\text { Aprobado } \\
\text { vivo }\end{array}$ & \multicolumn{1}{c|}{2009} & 2010 & \multicolumn{1}{|c|}{2011} \\
\hline Asociación & 5.328 .400 & 3.610 .000 & 891.060 & 1.522 .428 & 2.101 .603 \\
\hline Cooperativa & 9.410 .000 & 9.032 .000 & 1.996 .578 & 2.560 .906 & 4.567 .671 \\
\hline Redes & 1.525 .119 & 1.354 .119 & 738.131 & 769.189 & 464.161 \\
\hline Fundación & 7.015 .500 & 6.895 .500 & 3.152 .302 & 3.554 .977 & 3.404 .145 \\
\hline Sociedad Capital & 3.785 .800 & 2.980 .000 & 1.419 .822 & 1.544 .180 & 2.305 .368 \\
\hline Otros & 673.000 & 613.000 & 492.527 & 467.658 & 480.777 \\
\hline Total & 27.757 .819 & 24.484 .619 & 8.690 .420 & 10.419 .339 & 13.323 .725 \\
\hline
\end{tabular}

Fuente: Memoria Fiare 2011. Datos a 31 de diciembre

El mayor saldo operativo se ha concedido para el País Vasco un $42 \%$ del total del crédito, seguido de Cataluña (14\%) y Andalucía (11,5\%). No obstante el mayor número de operaciones se localiza en Cataluña igual que en 2010, Madrid ha aprobado para el ejercicio REVESCO No 109 - MONOGRÁFICO: La financiación complementaria y la respuesta de la economía social: la situación del "des-crédito" bajo la crisis financiera -

ISSN: 1885-8031 - www.ucm.es/info/revesco 
siguiente un paquete importante de financiación, mientras que se consolidan Andalucía y Valencia como los territorios con mayor incremento de préstamos sin oficina presencial (concentran el $13 \%$ y $10 \%$ respectivamente del saldo total de crédito).

Los tipos de operaciones son mediante avales (1 operación), cuenta corriente (67), préstamos hipotecarios (17) o personales (19). Se han incrementado en número las operaciones en cuenta de crédito (de 57 en 2010 a 67 en 2011) que sin embargo no suponen en sí un aumento de volumen sino que éste se ha mantenido prácticamente constante en ambos años, mientras que en las operaciones de hipotecario (de 15 a 17) un incremento en el número de operaciones si ha implicado un crecimiento del volumen de un $50 \%$.

A continuación se muestra una relación de proyectos financiados en el ejercicio 2011 (tabla 11).

Tabla 11. Relación de Proyectos financiados por Fiare (no se incluyen todos)

\begin{tabular}{|l|l|l|l|l|}
\hline \multicolumn{1}{|c|}{ Proyecto } & \multicolumn{1}{|c|}{ Sector } & Forma jurídica & \multicolumn{1}{c|}{ Importe (€) } & \multicolumn{1}{c|}{$\begin{array}{c}\text { Año finan. } \\
\text { /Ámbito }\end{array}$} \\
\hline $\begin{array}{l}\text { Fundación El } \\
\text { Sembrador }\end{array}$ & $\begin{array}{l}\text { Economía } \\
\text { solidaria/inclusión }\end{array}$ & Fundación & 72.500 & 2011 / Estatal \\
\hline $\begin{array}{l}\text { Clade Grupo } \\
\text { empresarial } \\
\text { cooperativo }\end{array}$ & $\begin{array}{l}\text { Economía } \\
\text { solidaria/inclusión }\end{array}$ & Cooperativa & & 2011 /Autonómico \\
\hline $\begin{array}{l}\text { Enreda, Soc. } \\
\text { Coop. Andaluza }\end{array}$ & $\begin{array}{l}\text { Economía } \\
\text { solidaria/inclusión }\end{array}$ & Asociación & 30.000 & 2011 / Estatal \\
\hline $\begin{array}{l}\text { Institut Aspace } \\
\text { Fundación } \\
\text { Privada }\end{array}$ & $\begin{array}{l}\text { Economía } \\
\text { solidaria/inclusión }\end{array}$ & Asociación & 800.000 & 2010 / Estatal \\
\hline $\begin{array}{l}\text { Iniciativas de } \\
\text { Economía } \\
\text { Alternativa y } \\
\text { Solidaria } \\
\text { (IDEAS) }\end{array}$ & $\begin{array}{l}\text { Economía } \\
\text { solidaria/inclusión }\end{array}$ & Cooperativa & 675.000 & 2012 / Estatal \\
\hline $\begin{array}{l}\text { Confederación } \\
\text { Regional de } \\
\text { AAVV de } \\
\text { Castilla La } \\
\text { Mancha }\end{array}$ & Valores sociales & Otras & 80.000 & $2011 /$ Autonómico \\
\hline $\begin{array}{l}\text { Asociación } \\
\text { Cultural } \\
\text { Barbiana }\end{array}$ & $\begin{array}{l}\text { Economía } \\
\text { solidaria/inclusión }\end{array}$ & Asociación & 60.000 & $2011 /$ Autonómico \\
\hline $\begin{array}{l}\text { Fundación Red } \\
\text { de Apoyo a la }\end{array}$ & $\begin{array}{l}\text { Economía } \\
\text { solidaria/inclusión }\end{array}$ & Fundación & 230.000 & 2011 / Estatal \\
\hline
\end{tabular}

REVESCO N 109 - MONOGRÁFICO: La financiación complementaria y la respuesta de la economía social: la situación del "des-crédito" bajo la crisis financiera - 


\begin{tabular}{|c|c|c|c|c|}
\hline $\begin{array}{l}\text { Integración } \\
\text { sociolaboral }\end{array}$ & & & & \\
\hline $\begin{array}{l}\text { Confederación } \\
\text { de } \\
\text { Consumidores } \\
\text { de Castilla La } \\
\text { Mancha }\end{array}$ & $\begin{array}{l}\text { Economía } \\
\text { solidaria/inclusión }\end{array}$ & Asociación & & 2011/Autonómico \\
\hline Nova Feina & $\begin{array}{l}\text { Economía } \\
\text { solidaria/inclusión }\end{array}$ & Asociación & 250.000 & 2011 / Estatal \\
\hline $\begin{array}{l}\text { Trabensol, Soc. } \\
\text { Coop. }\end{array}$ & $\begin{array}{l}\text { Economía } \\
\text { solidaria/inclusión }\end{array}$ & Cooperativa & & 2011 / Estatal \\
\hline $\begin{array}{l}\text { Ecoortiga, } \\
\text { S.Coop. } \\
\text { consumo } \\
\text { ecológico }\end{array}$ & Agroecología & Cooperativa & 85.000 & 2008 / Estatal \\
\hline Andaira & $\begin{array}{l}\text { Economía } \\
\text { solidaria/inclusión }\end{array}$ & Asociación & 15.000 & 2011 / Estatal \\
\hline $\begin{array}{l}\text { Promove } \\
\text { iniciativa social }\end{array}$ & $\begin{array}{l}\text { Economía } \\
\text { solidaria/inclusión }\end{array}$ & Cooperativa & & / Estatal \\
\hline
\end{tabular}

Fuente: elaboración propia a partir de Memorias Fiare (2011)

\section{CONCLUSIONES}

Las cooperativas y la banca social, en general, han nacido como una respuesta de la sociedad civil frente a un sistema financiero dominado por una banca capitalista, que no atiende sus necesidades ni responde a sus valores. Por ello, los dos elementos que han caracterizado a estas formas alternativas de hacer banca han sido la vocación de inclusión financiera, por una parte, y el respeto por unos principios éticos y sociales. Al estudiar su génesis y su evolución, en especial tras la actual crisis económica y financiera, se pueden sistematizar las siguientes conclusiones:

1. Entre el origen de las cooperativas de crédito y el de las instituciones de microcrédito o la banca social hay un lapso de unos 100 años. En consecuencia, aún manteniendo la vigencia de sus principios fundadores, las cooperativas han ido adaptándose a la nivelación del terreno de juego impuesto por los legisladores y a una competencia cada vez mayor. Por el contrario, las instituciones de microcrédito y la banca social presentan la frescura de la novedad y la virtualidad de ser una respuesta ad hoc a demandas recientes, como el crédito para los más pobres o las finanzas responsables. Todas ellas

REVESCO No 109 - MONOGRÁFICO: La financiación complementaria y la respuesta de la economía social: la situación del "des-crédito" bajo la crisis financiera - 
tienen mucho en común y pueden, y deben, compartir la experiencia de unas y la innovación de las otras.

2. La evolución de la actividad económica y financiera ha incentivado una tendencia a homogeneizar la actividad de todo tipo de intermediarios, incluidos los del "tercer sector". Estas últimas entidades de crédito se han ido aproximando en el negocio y en la forma de actuar a las entidades lucrativas, compartiendo, por inercia, unos mismos objetivos. Este fenómeno ha generado en ocasiones colisiones de cultura de negocios, la aparición de personalismos y la proliferación de conductas ajenas a los valores éticos, cuanto no vulneradoras de la propia legalidad. Esta colisión fue más evidente en el caso de las cajas de ahorros, lo que desembocó en el colapso sufrido ante el estallido de la burbuja inmobiliaria.

3. Todo ello ha generado un descrédito respecto al sistema bancario. Ahora bien, ¿está la sociedad efectivamente sensibilizada de este alejamiento de los principios virtuosos por parte del sistema financiero? ¿lo ve como algo normal y consustancial al negocio bancario, y por tanto inevitable? Parece que la sociedad en su conjunto ha interiorizado la mentalidad liberal individualista. Sin embargo, la percepción de la crisis actual exige un rearme ético y una revalorización de lo colectivo frente al culto a lo individual.

4. En España las cooperativas de crédito han permanecido relativamente al margen de las mayores turbulencias de la crisis, en parte aisladas a causa de sus propias características. Precisamente, estas peculiaridades fueron entendidas durante el período de expansión del crédito como unas "peligrosas debilidades", que dificultaban participar de pleno en la exuberancia financiera.

5. Ante la concentración que se avecina en el sistema financiero arrecia el riesgo de una oligopolización potencialmente peligrosa por el control de unos pocos agentes financieros. Ante esta situación, se revaloriza el papel de la banca alternativa, necesaria para una saludable biodiversidad.

REVESCO No 109 - MONOGRÁFICO: La financiación complementaria y la respuesta de la economía social: la situación del "des-crédito" bajo la crisis financiera - 
6. El incremento del ahorro directo e indirecto de las finanzas éticas es relevante por el significado que sugiere en un año, el 2011, en el que las entidades que han sufrido mayor descrédito han experimentado significativas retiradas de depósitos, en un contexto de elevados tipos de interés de los depósitos bancarios y, sobre todo, de los títulos del Estado.

7. Un imbricado de redes solidarias permite aproximar la financiación y el ahorro solidario a la posterior materialización en proyectos. La articulación sobre la base de redes mantiene la cercanía al territorio, y deja operativas las vías de acceso de las personas ahorradoras responsables y de las organizaciones que trabajan con personas vulnerables para poder crear las condiciones de acceso al crédito.

En definitiva, tras la experiencia se hace necesaria una reflexión en el sector de banca social y cooperativa a fin de conciliar nuevas situaciones con los viejos principios. Su viabilidad depende de una doble percepción. En primer lugar, conseguir que las autoridades financieras y los agentes económicos perciban la cooperativa como una forma jurídica apropiada para desenvolverse en un entorno capitalista, manteniendo unas peculiaridades especiales. En segundo lugar, conseguir que sus socios y clientes perciban un trato "diferente" al que pueden ofrecerle otros tipos de empresa.

\section{BIBLIOGRAFÍA}

ALMAGRO GARCIA, J.J. (coord.). Responsabilidad social: una reflexión global sobre la RSE, Madrid: FT Prentice Hall, 2010.

ANGUREN MARTIN, R.; MARQUÉS SEVILLANO, J.R. Cooperative and saving Banks in Europe: Nature, challenges and perspectives, Estabilidad Financiera, n 20, 2011, 130 p. ARGANDONA RAMIZ, A. Can corporate social responsibility help us understand the credit crisis? Working Paper IESE, Pamplona: Universidad de Navarra, 2009, 25 p.

ARMENDÁRIZ, B.; LABIE, M. (eds.). The Handbook of Microfinance, London-Singapore: World Scientific Publishing, 2011.

AZMI, R.A. Cooperative Finance and Sustainability After the Financial Crisis. En: SUN, W.; LOUCHE, C.; PÉREZ, R., Finance and Sustainability: Towards a New Paradigm? A REVESCO No 109 - MONOGRÁFICO: La financiación complementaria y la respuesta de la economía social: la situación del "des-crédito" bajo la crisis financiera - 
Post-Crisis Agenda (Critical Studies on Corporate Responsibility, Governance and Sustainability, vol. 2), London: Emeral Group., 2011.

BAHÍA ALMANSA, B. El microcrédito como instrumento de financiación al servicio de las entidades de economía social. Especial referencia al instrumento europeo de microfinanciación Progress. REVESCO-Revista de Estudios Cooperativos, $\mathrm{n}^{\circ} 106,3^{\circ}$ cuatrimestre, 2011, p. 33-54.

BERNAL CARRETERO, F. Finanzas alternativas, éticas y solidarias. El caso andaluz, Sevilla: Atrapasueños, 2011.

BETTIGNIES, H.C. DE; LÉPINEUX, F. (eds.) Finance for a Better World. The Shift Toward Sustainability, London: Palgrave Macmillan, 2009.

BOATRIGHT, J.R. Ethics in Finance, Malden Mass: Blackwell, 2008

BOSCIA, V., CARRETTA, A. (eds.). Cooperative banking: innovations and developments. Basingstoke, UK: Palgrave Macmillan Studies in Banking and Financial institutions, 2009.

CABALEIRO CASAL, M.J., RODRÍGUEZ PARADA, S. Sociedades cooperativas de banca alternativa. REVESCO-Revista de Estudios Cooperativos, $\mathrm{n}^{\circ}$ 95, $2^{\circ}$ cuatrimestre, 2008, p. 44-64.

CASTRO COTÓN, M., ROMERO CASTRO, N. Cooperativas de crédito y banca ética ¿un camino por explorar?. Ciriec-España, Revista de Economía Pública, Social y Cooperativa, $\mathrm{n}^{\mathrm{o}} 72,2011$, p. 263-300.

CHAVES ÁVILA, R. y SOLER TORMO, F. El gobierno de las cooperativas de crédito en España. Valencia: CIRIEC-España, 2004.

CANNING, D.; JEFFERSON, C.W.; SPENCER, J.E. Optimal credit rationing in nor-forprofit financial institutions. Discussion Paper Series. Cambrigde, Mass: Harvard Institute of Economic Research. Harvard University, 1999.

CEA MOURE, R. La Responsabilidad Social Corporativa en las entidades bancarias de la Unión Europea: análisis empírico y propuesta de modelo normalizado, Madrid: La Ley, 2012.

CLERCK, De. Ethical Banking. En: ZSOLNAI, L. (ed.), Ethical Prospects: Economy, Society, and Environment, Berlin, Heildelberg, New York: Springer, 2009, p. 209-227.

REVESCO No 109 - MONOGRÁFICO: La financiación complementaria y la respuesta de la economía social: la situación del "des-crédito" bajo la crisis financiera - 
CUESTA GONZÁLEZ, M. DE LA; FERNÁNDEZ OLIT, B.; VÁZQUEZ OTEO, O. Razón de ser de la banca ética: experiencias internacionales y nacionales, Madrid: Fundación de las Cajas de Ahorros, 2006.

CUEVAS, C.E., FISHER, K.P. Cooperative Financial Institutions. World Bank Working Paper $\mathrm{n}^{\circ}$ 82, 2006.

DAVIS, K. Credit Union Governance and Survival of the Cooperative form. Journal of Financial Services Research, $\mathrm{n}^{\mathrm{o}} 19,2001$, p. 197-210

DE LA DEHESA ROMERO, G. La primera crisis financiera del siglo XXI: Orígenes, detonantes, efectos y remedios, Madrid: Alianza Editorial, 2009.

DRAYTON, B. Emprendedores sociales. Todos podemos cambiar el mundo. Barcelona: Plataforma editorial, 2011.

FONTEYNE, W. Cooperative Banks in Europe Policy Issues. IMF Working Papers WP/07/159, 2007.

FULTON, M.; HUETH, B. Cooperative conversions, Failures and Restructuring: An Overview. Journal of Cooperatives, Vol. 23, 2009.

GARCÍA RODRÍGUEZ, F.; DÍAZ PERDOMO, Y. Los microcréditos como herramienta de desarrollo: revisión teórica y propuesta piloto para el África subsahariana. Ciriec-España, Revista de Economía Pública, Social y Cooperativa, no 70, 2011, p. 101-126.

GIDE, C. La cooperación como programa económico y otros textos, Zaragoza, AECOOP, 1974

HART, O.; MOORE, J. Cooperatives vs. Outside ownership. Working Paper 6421. National Bureau of Economic Research, Inc. Cambridge. Mass, 1998.

JACKSON, K. Virtuosity in business: invisible law guiding the invisible hand, Philadelphia: University of Pennsylvania, 2012.

KARLAN, D.; GOLDBERG, N. Microfinance Evaluation Strategies: Notes in Methodology and Findings", En: ARMENDÁRIZ, B.; LABIE, M. (eds.), The Handbook of Microfinance, London-Singapore: World Scientific Publishing, 2011.

LIPOVETSKY, G. Metamorfosis de la cultura liberal. Ética, medios de comunicación y empresa, Madrid: Anagrama, 2002.

MELIAN NAVARRO, A.; CAMPOS CLIMENT, V. Emprendedurismo y economía social como mecanismos de inserción sociolaboral en tiempos de crisis. REVESCO-Revista de Estudios Cooperativos, $\mathrm{n}^{\circ}$ 100, monográfico, 2010, p.43-67.

REVESCO No 109 - MONOGRÁFICO: La financiación complementaria y la respuesta de la economía social: la situación del "des-crédito" bajo la crisis financiera -

ISSN: 1885-8031 - www.ucm.es/info/revesco 
MELIÁN NAVARRO, A.; SANCHIS PALACIO, J.R.; SOLER TORMO, F. El Crédito Cooperativo como instrumento financiero para el fomento del emprendimiento en tiempos de crisis. Ciriec-España, Revista de Economía Pública, Social y Cooperativa, nº 68, 2010, p. $111-139$

OBSERVATORIO DE RESPONSABILIDAD SOCIAL CORPORATIVA, Informe Anual, (varios años), Disponible en Internet http://www.observatoriorsc.org/images/stories/audio/Proyectos/Informe_MemoriasRSC_2 011_completo.pdf

OBSERVATORIO ESPAÑOL DE LAS FINANZAS ETICAS. Barómetro de las Finances Étiques i Solidàrias. Varios años, Disponible en Internet http://www.fets.org/caes/fets/lobservatori-de-les-finances-etiques

OBSERVATORIO ESPAÑOL DE LAS FINANZAS ETICAS. Llibre d' entitats de les Finances Étiques i Solidàrias. Edita FETS, 2012.

OLMEDO CIFUENTES, I.; MARTÍNEZ LEÓN, I.; ARCAS LARIO, N.; LONGINOS MARIN, J. Relación circular entre ética, responsabilidad social y reputación de las cooperativas. REVESCO-Revista de Estudios Cooperativos, $\mathrm{n}^{\circ}$ 107, $1^{\circ}$ cuatrimestre, 2012, p. $129-154$.

PROYECTO FIARE. Memoria anual año 2011. Información disponible en internet http://www.proyectofiare.com

PALOMO ZURDO, R.; SANCHIS PALACIO, J.R., SOLER TORMO, F. (2010), "Las entidades financieras de economía social ante la crisis financiera: un análisis de las cajas rurales españolas", REVESCO-Revista de Estudios Cooperativos, $\mathrm{n}^{\circ}$ 100, número extraordinario, 2010, p. 101-133.

REINHART, C.; ROGOFF, K. This time is Different, Eight Centuries of Financial Folly, 2010. Disponible en internet http://www.economics.harvard.edu/files/faculty/51_This_Time_Is_Different.pdf

RIZKALLAH, E., BUENDÍA MARTÍNEZ, I. Corporate Social Responsability in the financial sector: are financial cooperatives Reddy to the challenge. Ciriec España, Revista de Economía Pública, Social y Cooperativa, no 73, 2011, p. 127-149.

SANGAUSTÍN FONS, M.V. Valores y ética empresarial: un enfoque sociológico, Madrid: Trotta, 2011.

SHILLER, R.J. Las finanzas en una sociedad justa, Deusto: Universidad, 2012. REVESCO No 109 - MONOGRÁFICO: La financiación complementaria y la respuesta de la economía social: la situación del "des-crédito" bajo la crisis financiera -

ISSN: 1885-8031 - www.ucm.es/info/revesco 
SOLER TORMO, F. La identidad cooperativa como garantía de futuro: Las cooperativas de crédito ante la trivialización de sus principios. Ciriec España, Revista de Economía Pública, Social y Cooperativa, nº 40, 2002, p. 215-242.

STIGLITZ, J. El precio de la desigualdad: el 1\% de la población tiene lo que el 99\% necesita, Madrid: Taurus, 2012.

SUN, W.; LOUCHE, C.; PÉREZ, R. Finance and Sustainability: Towards a New Paradigm? A Post-Crisis Agenda (Critical Studies on Corporate Responsibility, Governance and Sustainability, vol. 2, London: Emeral Group, 2011.

VELÁSQUEZ, M. Business Ethics. Case and Concepts (6 ${ }^{\text {th }}$ ed.), London: Pearson, 2006.

WEBER, O.; REMER, S. (eds.). Social Banks and the Future of Sustainable Finance, London-New York: Routledge, 2011.

WEISBROD, B. A. (ed.) To profit or not to profit. The commercial transformation of the nonprofit sector. Cambridge University Press, UK., 1998.

WORLD BANK (2011), Finance for All? Policies and Pitfalls in Expanding Access, Washington: The World Bank.

REVESCO No 109 - MONOGRÁFICO: La financiación complementaria y la respuesta de la economía social: la situación del "des-crédito" bajo la crisis financiera - 